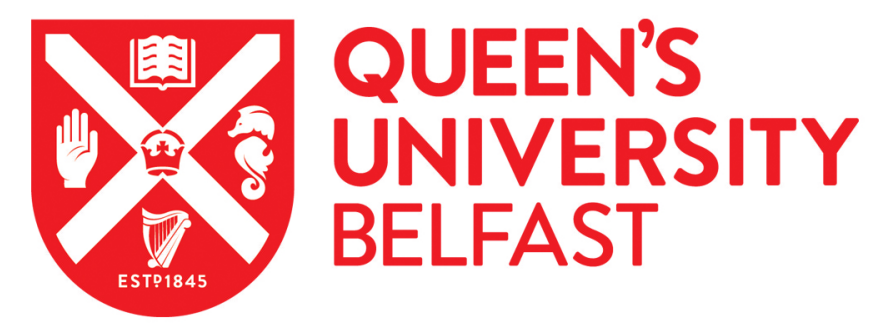

\title{
Modeling G-L-L-S Reactor: A Case of Hydrogenation of Nitrobenzene
}

\author{
Sharma, D. V., Patwardhan, A. W., \& Ranade, V. V. (2017). Modeling G-L-L-S Reactor: A Case of \\ Hydrogenation of Nitrobenzene. Industrial and Engineering Chemistry Research, 56(6), 1404-1415. \\ https://doi.org/10.1021/acs.iecr.6b03744
}

\section{Published in:}

Industrial and Engineering Chemistry Research

\section{Document Version:}

Peer reviewed version

\section{Queen's University Belfast - Research Portal:}

Link to publication record in Queen's University Belfast Research Portal

\section{Publisher rights}

(C) 2017 American Chemical Society.

This work is made available online in accordance with the publisher's policies. Please refer to any applicable terms of use of the publisher.

\section{General rights}

Copyright for the publications made accessible via the Queen's University Belfast Research Portal is retained by the author(s) and / or other copyright owners and it is a condition of accessing these publications that users recognise and abide by the legal requirements associated with these rights.

Take down policy

The Research Portal is Queen's institutional repository that provides access to Queen's research output. Every effort has been made to ensure that content in the Research Portal does not infringe any person's rights, or applicable UK laws. If you discover content in the Research Portal that you believe breaches copyright or violates any law, please contact openaccess@qub.ac.uk. 


\title{
MODELING G-L-L-S REACTOR: A Case of Hydrogenation of Nitrobenzene
}

\author{
Deepankar V Sharma ${ }^{1,2}$, Ashwin W Patwardhan ${ }^{2}$ and Vivek V \\ Ranade $^{1,3 *}$ \\ ${ }^{1}$ Chemical Engineering and Process Development Division \\ CSIR - National Chemical Laboratory \\ Pune 411008, India \\ ${ }^{2}$ Chemical Engineering Division
Institute of Chemical Technology \\ Mumbai 400019, India \\ ${ }^{3}$ School of Chemistry and Chemical Engineering \\ Queen's University Belfast, Belfast, NI, UK \\ [V.Ranade@qub.ac.uk]
}

* Author to whom correspondence should be addressed 


\begin{abstract}
Gas-liquid-liquid-solid (GLLS) reaction systems are often encountered in manufacturing of fine and specialty chemicals. More often than not such reaction systems involve multiple reactions and selectivity towards desired component always poses challenges. An adequate understanding of various parameters affecting GLLS reactor performance is essential to develop strategies for realizing desired selectivity. In this work, a comprehensive reaction engineering model for simulating four phase hydrogenation reactions have been developed. A generalized mixing cell based framework for a reaction system with four interacting phases (gas [G], aqueous [L], organic [L] and solid catalyst [S]) was developed. The model is written in a general way so as to specify one of the liquid phases as a continuous phase and other three phases are dispersed into it. In each cell, vapor space is included. The model includes the possibility of evaporation of solvent and internal condensation (in vapor space). The model can also be applied for a dead end (from a perspective of reacting gas) reactor. Model equations were solved using MATLAB. The equations and solution methodology was verified by comparing numerical solutions with available solutions of various limiting cases. A case of four phase hydrogenation of nitrobenzene to para amino phenol and aniline was considered to illustrate the application of the developed model. Key findings from the model were validated by comparing with laboratory scale experimental data. The model was then used to develop insights and guidelines for enhancing selectivity towards desired product. The developed model and presented results will be useful to develop general guidelines for design and optimization of GLLS reactors.
\end{abstract}

Keywords

GLLS reactor, Hydrogenation, Nitrobenzene, p-Aminophenol, Aniline 


\section{Introduction}

Gas-liquid-liquid-solid (GLLS) systems are employed extensively for manufacturing of fine and speciality chemicals. As the name indicates, these reaction systems consist of four phases each having a specific purpose in the reaction system. Gas and solid phases generally have a reactant gas (along with vapours of volatile components) and catalyst. The two liquid phases are obviously immiscible, among which one is acting as a continuous phase in which the secondary liquid phase, solid and gas phases are dispersed. The catalyst may be present in one of the liquid phases (continuous or dispersed) which becomes the reaction phase. This is sometimes achieved using various chemical methods like use of a complex forming agent as in hydrogenation of benzene ${ }^{[1,2]}$ or adjusting the $\mathrm{pH}$ of aqueous phase in the case of hydrogenation of cinnamaldehyde ${ }^{[3,4]}$. Due to these two characteristics a four phase system becomes sensitive to parameters like reaction conditions, hold up, mass transfer etc. Furthermore, any modelling attempt must incorporate the interaction between reaction, thermodynamic and transport parameters.

In a three phase (GLS) reaction system the reactants, solvent and products (liquid/dissolved solid products) are present in the same phase. This might lead to further reaction leading to formation of side products causing losses in terms of selectivity of the commercially desired product. GLLS systems typically are used where abetting or abatement of a reaction or set of reactions is required to increase the selectivity of a particular product. The presence of a secondary phase is of key importance to this objective as the subsequent mass transfer between liquid phases may alter the overall reaction scheme ${ }^{[5]}$. In four phase systems the desired product or intermediate is absorbed by the secondary phase where it may undergo a separate set of reactions that finally leads to higher selectivity. In some cases, the product is simply isolated in an immiscible solvent where it can be easily separated downstream ${ }^{[1,2,6]}$.

There have been some attempts to model four phase systems as shown in Table 1. In many cases the model was used to back calculate kinetic parameters by fitting the experimental data; for example: Lehtonen et al (1998) ${ }^{[7]}$ and Roy et al (2005) ${ }^{[8]}$. Most of such models use volumetric rate of reaction and not the rate at the surface of the catalyst. The rates of formation of final products were back calculated using the experimental data ${ }^{[9,4,10]}$. Lekhal et al ${ }^{[11]}$ attempted to define reaction regime based on the relative rates of mass transfer and reaction. 
Garf et al ${ }^{[5]}$ have included non-isothermal effects. However most of the other models have considered isothermal mode of operation. In many of these earlier models, intricacies of four phase systems were not adequately considered ${ }^{[10,9,12]}$. In many studies, reacting mass is assumed to be saturated with hydrogen which is not usually the case. None of these models have considered the evaporation of solvents/reactants and its subsequent effect on partial pressure of hydrogen and solubility of hydrogen in the reaction phase ${ }^{[11,13,9,33]}$.

Hence, there is a need for an improved model that considers gas-liquid as well as liquid-liquid mass transfer and adequately accounts for transfer of species across two liquid phases. It is important to consider unsteady processes and existence of vapour space above GLLS dispersion in the reactor to adequately represent real life GLLS reactor. Such a model may allow simulation of reactor with evaporating/ boiling solvent and is needed for obtaining new insights on possible process intensification. Such an attempt is made in this work. A flexible generic GLLS reactor model was developed in this work. The usefulness of model is illustrated here by considering the case of hydrogenation of nitrobenzene to p-aminophenol as a model system.

p-Aminophenol (pAP) is an important chemical produced on a large scale. Its fundamental use is in production of analgesics like paracetamol. Previously, pAP was produced by iron acid reduction of $\mathrm{p}$-nitro-chlorobenzene or $\mathrm{p}$-nitrophenol ${ }^{[14]}$. The major disadvantage of this multistep process is that it produces $1.2 \mathrm{~kg}$ of iron oxide sludge per $\mathrm{kg}$ of product. Hence, the process has been rendered unusable as it is environmentally unfeasible and very inefficient. Henke and Vaughen (1940) ${ }^{[15]}$ first reported a process for pAP by hydrogenation of nitrobenzene using Pt catalyst and mineral acid (other examples are listed in Table 2). Many of these research articles explored different catalyst for the reaction ${ }^{[16,9,17]}$.

Recently, Rode et al (1999 and 2001) ${ }^{[9,13]}$ described the reaction and modelling of hydrogenation of nitrobenzene (NB) to pAP in considerable detail. NB in the presence of hydrogen and catalyst forms an intermediate phenylhydroxylamine (PHA) which further hydrogenates to form aniline with a very high selectivity (>90\%). However, if a low pH aqueous phase is added to the reaction mixture the reaction changes its path completely to form pAP as the major product. This addition of an immiscible phase with seemingly no interaction with the reaction itself make a very interesting and useful study to understand both qualitatively and quantitatively the process of four phase reaction systems. 
The reason behind this major shift in the selectivity in favour of pAP is because of presence of the immiscible second liquid phase. Due to the presence of an aqueous phase both aniline and PHA enter into the aqueous phase where due to the presence of mineral acid $\left(\mathrm{H}^{+}\right.$ions $)$PHA undergoes further reaction. This reaction is called Bamberger rearrangement where the hydroxyl group attached at the $\beta$ position of nitrogen migrates to the para position with respect to $\left(-\mathrm{NH}_{2}\right)$ on the benzene ring. Because of this rearrangement pAP is formed in the aqueous phase. Another use of the mineral acid is that it reacts with the pAP and forms a salt, due to this the concentration of both pAP and PHA are very low in the aqueous medium and the concentration gradient responsible for mass transfer of PHA from organic to aqueous phase is maintained. The complete reaction scheme is shown in Figure $1^{[9]}$.

The focus of the present work is on the formulation of a comprehensive reactor-engineering model for GLLS reactor. A generalized framework for a single well mixed cell (and associated with vapour space) was developed. The single mixing cell model can be extended, using the computational fluid dynamics (CFD) framework, to formulate "network of mixing cells" to represent more real-life reactor configurations and operating conditions. In the present work, we have presented results with a single mixing cell which are representative of an ideal CSTR. The model equations, numerical solution and obtained results are discussed in the following.

\section{Mathematical model of GLLS reactor}

The schematic representation of single cell framework is shown in Figure 2. There are two liquid phases in the aforementioned mixing cell representing continuous phase and dispersed phase. The representative solid phase is the catalyst and it may be present in either or both liquid phases. The inlet flow rate of gas may depend on gas sparged in the reactor as well as gas induced by impeller (in case if gas inducing impeller is used). The model equations are presented in the following:

Mass balance equation for component ' $\mathrm{i}$ ' in liquid phase ' $\mathrm{P}$ ' can be written as:

$$
\frac{d\left(V_{D, n} \varepsilon_{n}^{P} \rho_{n}^{P} x_{n, i}^{P}\right)}{d t}=\dot{m}_{n-1, i}^{P}-\dot{m}_{n, i}^{P}+\sum_{k=1}^{M}\left(V_{D, n} \varepsilon_{n}^{P} R_{k, i}^{P} M w_{i}\right)+V_{D, n} S_{n, i}^{P} M w_{i}+V_{D, n} S_{n, i}^{g} M w_{i}
$$

Where $\mathrm{V}_{\mathrm{D}, \mathrm{n}}$ denotes volume of GLLS dispersion in mixing cell ' $\mathrm{n}$ '. $R_{k, i}^{P}$ denotes rate of formation of component ' $\mathrm{i}$ ' in phase ' $\mathrm{P}$ ' via reaction ' $\mathrm{k}$ '. 
The overall mass balance of liquid phase 'P' can be written by summing Equation (1) over all components as:

$\frac{d\left(V_{D, n} \varepsilon_{n}^{P} \rho_{n}^{P}\right)}{d t}=\dot{m}_{n-1}^{P}-\dot{m}_{n}^{P}+\sum_{i=1}^{N} \sum_{k=1}^{M}\left(V_{D, n} \varepsilon_{n}^{P} R_{k, i}^{P} M w_{i}\right)+\sum_{i=1}^{N} V_{D, n} S_{n, i}^{P} M w_{i}+\sum_{i=1}^{N} V_{D, n} S_{n, i}^{g} M w_{i}$

The source terms appearing in these equations are for reaction, liquid - liquid mass transfer and gas - liquid mass transfer.

Energy balance over the liquid phase ' $\mathrm{P}$ ' can be written as:

$$
\begin{aligned}
& \frac{d\left(V_{D, n} \varepsilon_{n}^{P} \rho_{n}^{P} C p_{n}^{P} T_{n}^{P}\right)}{d t}=\dot{m}_{n-1}^{P} C p_{n-1}^{P} T_{n-1}^{P}-\dot{m}_{n}^{P} C p_{n}^{P} T_{n}^{P}+\sum_{k=1}^{M}\left(V_{D, n} \varepsilon_{n}^{P} R_{k, i}^{P} M w_{i} \Delta H_{k}\right) \\
& +\sum_{i=1}^{N} V_{D, n} S_{n, i}^{P} M w_{i} \alpha+\sum_{i=1}^{N} V_{D, n} S_{n, i}^{g} M w_{i} \beta+\Delta H_{e n v}+\sum_{P=1}^{Z} \Delta H_{P}
\end{aligned}
$$

The sources appearing in Equation (3) represent enthalpy of reaction, evaporation and solution and the enthalpy related to the mass transfer. The expressions for $\alpha, \beta$ and $\gamma$ are given below. $\Delta \mathrm{H}_{\mathrm{env}}$ and $\Delta \mathrm{H}_{\mathrm{P}}$ represent the heat exchange between coolant and phases respectively.

Mass balance for dispersed and overhead gas phase can be written as:

$$
\begin{aligned}
& \frac{d\left(V_{D, n} \varepsilon_{n}^{g} \rho_{n}^{g} x_{n, i}^{g}\right)}{d t}=\dot{m}_{n-1, i}^{g}-\dot{m}_{n, i}^{g}+\sum_{k=1}^{M}\left(V_{D, n} \varepsilon_{n}^{g} R_{k, i}^{g} M w_{i}\right)+V_{D, n} S_{n, i}^{g} M w_{i} \\
& +F_{\text {in }} \rho_{n}^{O H} x_{n, i}^{O H}-F_{\text {out }} \rho_{n}^{g} x_{n, i}^{g} \\
& \frac{d\left(V_{D, n} \varepsilon_{n}^{g} \rho_{n}^{g}\right)}{d t}=\dot{m}_{n-1}^{g}-\dot{m}_{n}^{g}+\sum_{i=1}^{N} \sum_{k=1}^{M}\left(V_{D, n} \varepsilon_{n}^{g} R_{k, i}^{g} M w_{i}\right)+\sum_{i=1}^{N} V_{D, n} S_{n, i}^{g} M w_{i}+F_{\text {in }} \rho_{n}^{O H}-F_{\text {out }} \rho_{n}^{g} \\
& \frac{d\left(V_{O H} \rho_{n}^{O H} x_{n, i}^{O H}\right)}{d t}=\dot{m}_{n-1, i}^{O H}-\dot{m}_{n, i}^{O H}+\sum_{k=1}^{M}\left(V_{O H} R_{k, i}^{O H} M w_{i}\right)-F_{\text {in }} \rho_{n}^{O H} x_{n, i}^{O H}+F_{\text {out }} \rho_{n}^{g} x_{n, i}^{g} \\
& \frac{d\left(V_{O H} \rho_{n}^{O H}\right)}{d t}=\dot{m}_{n-1}^{O H}-\dot{m}_{n}^{O H}+\sum_{i=1}^{N} \sum_{k=1}^{M}\left(V_{O H} R_{k, i}^{O H} M w_{i}\right)-F_{\text {in }} \rho_{n}^{O H}+F_{\text {out }} \rho_{n}^{g}
\end{aligned}
$$


$F_{\text {in }}$ is the volumetric gas flow rate to the reactor: either sparged or induced by devices like jet ejectors or gas inducing impellers and is an input data to the model. Rest of the terms shown are similar to the liquid phase mass balance. It is to be noted that direct interaction between the liquid phase and the overhead space is negligible in comparison to the dispersed gas phase as the area available for heat and mass transfer between liquid and dispersed gas is far greater.

Energy balance for dispersed and overhead gas phase can be written as:

$$
\begin{aligned}
& \frac{d\left(V_{D, n} \varepsilon_{n}^{g} \rho_{n}^{g} C p_{n}^{g} T_{n}^{g}\right)}{d t}=\dot{m}_{n-1}^{g} C p_{n-1}^{g} T_{n-1}^{g}-\dot{m}_{n}^{g} C p_{n}^{g} T_{n}^{g}+\sum_{k=1}^{M}\left(V_{D, n} \varepsilon_{n}^{g} R_{k, i}^{g} M w_{i} \Delta H_{k}\right) \\
& -\sum_{i=1}^{N} V_{D, n} S_{n, i}^{g} M w_{i} \chi+F_{\text {in }} \rho_{n}^{O H} C p_{n}^{O H} T_{n}^{O H}-F_{\text {out }} \rho_{n}^{g} C p_{n}^{g} T_{n}^{g}+\sum_{P=1}^{Z} \Delta H_{P} \\
& \frac{d\left(V_{O H} \rho_{n}^{O H} C p_{n}^{O H} T_{n}^{O H}\right)}{d t}=\dot{m}_{n-1}^{O H} C p_{n-1}^{O H} T_{n-1}^{O H}-\dot{m}_{n}^{O H} C p_{n}^{O H} T_{n}^{O H}+\sum_{k=1}^{M}\left(V_{O H} R_{k, i}^{O H} M w_{i} \Delta H_{k}\right) \\
& -F_{\text {in }} \rho_{n}^{O H} C p_{n}^{O H} T_{n}^{O H}+F_{\text {out }} \rho_{n}^{g} C p_{n}^{g} T_{n}^{g}
\end{aligned}
$$

The sum of gas and liquid phase mass balances results in overall mass balance as:

$$
\frac{d\left(V_{D, n}\left(\sum_{P=1}^{Z-1} \varepsilon_{n}^{P} \rho_{n}^{P}+\varepsilon_{n}^{g} \rho_{n}^{g}\right)+V_{O H} \rho_{n}^{O H}\right)}{d t}=\sum_{P=1}^{Z} \dot{m}_{n-1}^{P}-\sum_{P=1}^{Z} \dot{m}_{n}^{P}
$$

In order to solve these model equations, additional correlations/equations for thermodynamic models, mass/heat transport, source terms, constitutive laws and closure/sub models are needed. These equations are given below.

Equation (10) was used to calculate volume of dispersion $\left(V_{D}\right)$. The volume of the overhead space was then calculated using specified volume of reactor $\left(V_{R}\right)$ as:

$$
V_{O H, n}=V_{R, n}-V_{D, n}
$$

Outlet flow rate of gas was calculated using bubble rise velocity $\left(\mathrm{V}_{\mathrm{b}, \mathrm{inf}}\right)$ and gas hold-up as:

$$
F_{\text {out }}=\varepsilon_{n}^{g} A_{R, n} V_{b, \text { inf }}
$$

Bubble rise velocity and bubble diameter ${ }^{[29,30]}$ were calculated as: 


$$
\begin{aligned}
& V_{b, \text { inf }}=0.71\left(g d_{B}\right)^{0.5} \\
& d_{B}=1.21 \frac{\sigma^{0.6}\left(\mu_{L} / \mu_{G}\right)}{\left(P_{R} / V_{L}\right)^{0.4} \rho_{L}^{0.2}}
\end{aligned}
$$

Source terms appearing in the model equations need to be formulated in order to close the model equations. The reaction source terms based on rate of formation of species i, via reaction $\mathrm{k}$ in phase $\mathrm{P}$ were formulated as:

$$
R_{k, i}^{P}=\alpha\left(\frac{A_{k, i}}{A_{k, r e f}}\right) k_{k} e^{\left(\frac{-\Delta E}{R T^{P}}\right)} \frac{\prod_{i=1}^{N} C_{n, i}^{P}{ }^{O_{k, i}}}{1+K_{k} e^{\left(\frac{-\Delta E}{R T^{P}}\right)} \prod_{i=1}^{N} C_{n, i}^{P}{ }^{O_{k, i}}}
$$

This generalized rate of reaction can be used for both power-law and for LanguimirHinshelwood kinetic expressions. Parameter $\alpha$ is concentration of catalyst in phase $(\mathrm{w} / \mathrm{w})$ for catalytic reactions and for non-catalytic reaction $\alpha$ is set to 1 . All the kinetic parameters are provided as input data and the concentrations were calculated from mass fractions as:

$$
\begin{aligned}
& C_{n, i}^{P}=\frac{x_{n, i}^{P} \rho_{n}^{P}}{M w_{i}} \\
& \rho_{n}^{P}=\frac{1}{\sum_{i=1}^{N} \frac{x_{n, i}^{P}}{\rho_{i}}}
\end{aligned}
$$

If the reaction phase is gaseous the density of reaction phase was calculated using Equations 18-19 (ideal gas law). From average molecular weight, mole fractions were calculated and using mole fraction phase properties like specific heat were determined as shown in Equations $20-21$.

$$
\begin{gathered}
M w_{n}^{g}=\frac{1}{\sum_{i=1}^{N} \frac{x_{n, i}^{P}}{M w_{i}}} \\
\rho_{n}^{g}=\frac{P_{R, n} M w_{n}^{g}}{R T^{g}}
\end{gathered}
$$




$$
\begin{gathered}
\theta_{n, i}^{P}=\frac{M w_{i}}{M w_{n}^{P}} \\
C p_{n}^{P}=\sum_{i=1}^{N} C p_{i} \theta_{n, i}^{P}
\end{gathered}
$$

The mass transfer rates were expressed as:

$$
S_{n, i}^{P}=\sum_{Q=1}^{Z-1} k_{p q}\left(C_{n, i}^{P}-C_{n, i}^{P, \text { int }}\right)
$$

Where $C^{\mathrm{P} \text {,int }}$ can be calculated using the following:

$$
\begin{aligned}
& k_{P}\left(C_{n, i}^{P}-C_{n, i}^{P, \text { int }}\right)=k_{Q}\left(C_{n, i}^{Q, \text { int }}-C_{n, i}^{Q}\right) \\
& C_{n, i}^{P, \text { int }}=k_{P Q} C_{n, i}^{Q, \text { int }}
\end{aligned}
$$

The parameters $\alpha, \beta$ and $\gamma$ were calculated appropriately depending on whether the solvent is evaporating or vapours are condensing as:

if $S_{n, i}^{P}<0$

$\alpha=C p_{n, i}^{Q} T_{n}^{Q}+\Delta H_{s o l}$

else

$\alpha=C p_{n, i}^{P} T_{n}^{P}$

If $S_{n, i}^{g}<0$

$\beta=C p_{n, i}^{g} T_{n}^{g}$

$\chi=C p_{n, i}^{g} T_{n}^{g}+\lambda_{i}$

else

$\beta=C p_{n, i}^{P} T_{n}^{P}+\lambda_{i}$

$\chi=C p_{n, i}^{P} T_{n}^{P}$

Other sub-models include the estimation of thermodynamic parameters like solubility and vapour pressure. Regular solution theory was used for estimation of solubility ${ }^{[18,32]}$. The 
hydrogen solubility in different species data was taken from various literature sources $[19,20,21$, 31].

$-\ln \left(x_{A}\right)=\ln \left(\frac{f_{A, l}}{f_{A}}\right)-\varphi_{s}^{2} v_{A} \frac{\left(\delta_{S}-\delta_{A}\right)}{R T}$

The heat transfer sources were formulated as:

$$
\begin{aligned}
& \Delta H_{P}=k_{P Q}\left(T_{P}-T_{Q}\right) \\
& \Delta H_{\text {env }}=h_{R}\left(T^{P, \text { Cont }}-T^{\text {Jacket }}\right)
\end{aligned}
$$

The model equations were solved using MATLAB. The ode15s solver suitable for solving differential algebraic equations was used. The ode15s solver uses modified backward difference formulae (BDFs) called the numerical difference formulae (NDFs) to discretize the set of equations and the equations are then solved using simple Newton iteration method ${ }^{[22]}$. The accuracy and order can be controlled using various options like tolerance and order provided in MATLAB. A second order solver with tolerance of $10^{-8}$ was used to solve these equations and the solution of the model was verified against various limiting cases that have analytical solution. Equations 1 to 10 were solved in their conservative form. More details of numerical solution are provided in the supplementary material (Supplementary information; Appendix 1).

\section{Results and Discussion}

The reactor model presented here was first used to simulate laboratory scale experiments to establish its applicability. The model was then used to develop general guidelines for four phase hydrogenations. A case of hydrogenation of nitrobenzene to para amino phenol was considered here for illustration.

\subsection{Comparison with the experimental data}

Two sets of experimental data emanating from the group of Rode and co-workers were selected. In the first set of experimental data (Rode et al ${ }^{[9]}$ ), part of the reported data was used 
to estimate kinetic parameters. The model predictions were then compared with the remaining part of experimental data.

Vaidya et al. ${ }^{[23]}$ (see supplementary information Appendix 2) reported experimental data from the experiments of NB hydrogenation with aqueous phase as a continuous phase over range of temperatures and pressures. The reported data of hydrogen absorption at three temperatures (323, 338, and $353 \mathrm{~K}$ ) was used to estimate parameters appearing in following kinetic expressions:

$$
\begin{aligned}
& r_{A N}=w k_{1} C_{H_{2}} \\
& r_{p A P}=\frac{w k_{2} C_{H_{2}}}{1+K C_{H_{2}}}
\end{aligned}
$$

The reported conversion and selectivity data was also used along with the hydrogen consumption data. The developed reactor model was able to fit the experimental data reasonably well (see Figure 3 for comparison). Using the estimated kinetic parameters, the model was used to simulate influence of pressure on hydrogen absorption, NB conversion and selectivity towards pAP. It can be seen from Figures $4 \mathrm{a}$ and $4 \mathrm{~b}$ that model was able to capture experimental data quite well.

Recently Rode and co-workers ${ }^{[26]}$ have carried out hydrogenation of NB at low pressures (less than 3 atm. hydrogen partial pressure) using different process. These reactions were carried out at higher temperature range (up to $383 \mathrm{~K}$ ) than that used by Vaidya et al. ${ }^{[23]}$. They have carried out experiments using hexane as a solvent for NB. Experiments were carried out in two sets: one with aqueous phase as a continuous phase and the second with organic phase as a continuous phase. Presence of hexane at higher operating temperature resulted in significant vapour pressure of solvents (hexane and water while immiscible form a low boiling azeotrope at $61{ }^{\circ} \mathrm{C}{ }^{[24]}$ ). A truncated NRTL model was used to estimate partial pressure of the evaporated solvents. Predicted vapour pressures agreed quite well with the experimental data (not shown here for the sake of brevity). It was also important to consider non-isothermal nature of operation since significant extent of reactions also occur during the reactor heat-up phase. Heat transfer from jacket, heat of reaction and solvent evaporation make the task of simulating reactor temperature non-trivial. The reactor model was used to simulate NB hydrogenation experiments with aqueous as continuous phase as well as with organic as continuous phase (see supplementary information Appendix 2 for more details). The comparison of model predictions 
with the experimental data of reactor temperature and hydrogen absorption is shown in Figure 5. It can be seen that reactor model successfully captures the experimental results. Substantial enhancement in rate of reaction because of addition of hexane as a solvent and maintaining organic as continuous phase on NB hydrogenation was captured correctly. More details of low pressure experiments cannot be discussed here because of the confidentiality constraints. However, it may be sufficient to state here that the reactor model was able to capture the key experimental data of conversion, selectivity, temperature and hydrogen consumption adequately. The model was then used to understand overall behaviour of GLLS hydrogenation reactors and to evolve general guidelines for enhancing their performance.

Figure $6 \mathrm{a}$ and $6 \mathrm{~b}$ shows the comparison of single phase and three phase models described earlier to the GLLS (4 phase model) and experimental results for dispersed reaction phase. Simulations were performed for the Vaidya et $\mathrm{al}^{[23]}$ system using single, 3 phase and 4 phase models for different values of kla-g (G-L mass transfer coefficient). The key points are listed below.

1. As single phase model does not account for mass transfer no change in conversion was reported, in 3-phase and 4 phase model conversion decreases with decrease in kla-g.

2. In GLLS model the overall resistance to mass transfer is higher as compared to 3 phase (GLS) model hence we see lower conversion in GLLS model than GLS model.

3. In Figure $6 \mathrm{~b}$ conversion is plotted against residence time for different values of kla-1 (L-L mass transfer coefficient), the impact of L-L mass transfer resistance cannot be modelled using the single phase or the 3 phase model.

The results at high mass transfer rates almost show no difference between the three models as the regime of operation is kinetic controlled itself. Hence, under such conditions the salient features of the GLLS model is not highlighted. However, under poor mass transfer condition and when the rate of reaction and mass transfer are comparable (which are incidentally a large percentage of the cases) the GLLS model results give more insights as they incorporate more physical phenomenon and have a greater range in which the model results are valid.

In addition to the conversion, selectivity, hydrogen consumption and temperature the GLLS reactor model is capable of simulating boiling of solvents in the reactor. This is of importance 
as the reaction is conducted in non-isothermal and under isobaric conditions. This implies that the vapour pressure of the solvents will change with respect to temperature and the partial pressure of hydrogen will be affected due to additional boiling/condensation. Hence, in order to have a non-isothermal model the boiling of solvents must be predicted with accuracy. Experiments were performed in which the reaction mixture was heated to temperature ranging from $70-100{ }^{\circ} \mathrm{C}$ and vapour pressure readings were taken. No catalyst and hydrogen was added hence there was no reaction during the course of experiments. This data was plotted with the simulated reactor pressure using the GLLS as shown in Figure 7. As can be seen from the figure that the simulated values agree with the experimental data. Hence, it can be said with confidence that the partial pressure of hydrogen was calculated with adequate accuracy during the simulations.

\subsection{Application of model for enhancing performance of GLLS reactor}

The model developed in the previous sections may be used for selecting reactor and reaction conditions for any four phase hydrogenation. There are many critical issues in a four phase reaction system that must be addressed before finalizing the design and operational parameters. It is important to understand interactions of heat and mass transfer with chemical reactions. Besides this, there are several other important parameters like selection of continuous phase, volume fraction of dispersed phase, whether the catalyst exists in continuous or dispersed phase and so on. The conversion and selectivity will also be function of other usual operating parameters as temperature, pressure and residence time. The model presented here will be very useful to quantitatively understand influence of these several variables and will guide the user to identify best operating conditions. In order to illustrate the application of model for such an exercise, simulated results are best presented in terms of dimensionless numbers.

$$
\begin{aligned}
& D a_{G-L}=\tau_{R} k_{G-L} a \\
& D a_{R x n}=\tau_{R} \frac{k_{2}}{1+K C_{H_{2}}} \approx \tau_{R} k_{2}
\end{aligned}
$$

The dimensionless number used here is a ratio of Damkholer number for reaction (Da-Rxn) and Damkholer number for mass transfer (Da-kla). This is the ratio of the reaction time scales and mass transfer time scales. The hydrogen solubility in NB and hexane range from $9 \times 10^{-4}$ to $6 \times 10^{-3}$ while the adsorption coefficient $(\mathrm{K})$ ranges from $7 \sim 15$. Hence the denominator 
expression $\left(1+\mathrm{KC}_{\mathrm{H} 2}\right)$ was approximated to 1 .The range of gas-liquid mass transfer coefficient selected was in between $10-0.01 \mathrm{~m} / \mathrm{s}^{[3]}$, while the upper limit coincides with the mass transfer coefficient in a jet ejector or gas inducing impeller while the lower limit represents extremely poor mass transfer cases.

The relevant data was taken from the illustration case considered here (hydrogenation of nitrobenzene). The catalyst location was found to be in organic phase from the cold flow experiments irrespective of whether organic phase is continuous or dispersed. Similar observations were made by Rode et al ${ }^{[26]}$ and Yamata et al et al ${ }^{[25]}$. The model was then used to carry out simulations over a wide range of mass transfer/ kinetic parameters (in terms of the ratio of two Damkohler numbers mentioned earlier). Key results are discussed in the following.

\subsubsection{Influence of continuous phase}

The first reactor operation parameter to be analysed is the selection of continuous phase, i.e. the reaction phase to be set as continuous or dispersed. There can be many different criteria for selection of continuous phase like specific heat, solubility etc. However, in this study the impact on conversion and selectivity is the only criteria considered for the selection of continuous phase. The continuous phase is in contact with both dispersed gas and liquid phases and as mass transfer plays a very important role in four phase reactions, it should be the main criteria on which the selection of continuous phase has to be based on.

The simulated results in the form of contour plot for conversion of NB and selectivity towards pAP at various values of $D a_{R x n} / D a_{k l a-g}$ and $D a_{R x n} / D a_{k l a-l}$ are presented in Figure 8 . All the data presented in this contour plot was generated using a fixed pressure (1 bar Hydrogen pressure) and residence time (1500 s). For $D a_{R x n} / D a_{k l a-g}<0.06$ and $D a_{R x n} / D a_{k l a-l}<0.28$ the overall rate of reaction falls in kinetically controlled regime. This means, that the gas-liquid mass transfer rate should be 15 and liquid-liquid mass transfer rate should be 3-3.5 times the rate of reaction at $80{ }^{\circ} \mathrm{C}$. The selectivity contour plot further reveals that gas liquid mass transfer coefficient does not have a significant effect on the selectivity of pAP and liquid-liquid mass transfer has a profound effect on the selectivity towards pAP. Figure 8 (a) \& (b) also point to an obvious 
conclusion that gas-liquid and liquid-liquid mass transfer coefficient should be very high for maximum conversion of $\mathrm{NB}$ and selectivity of $\mathrm{pAP}$.

Figure 9 shows the variation of conversion and selectivity with the change in $D a_{R x n} / D a_{k l a-g}$ and $D a_{R x n} / D a_{k l a-l}$ for reaction/organic phase set as continuous phase. Simulations were performed at 1 bar hydrogen pressure and $1500 \mathrm{~s}$ residence time. As seen in Figure 9 (a), as the reaction phase is continuous and hydrogen is directly dissolving into the reaction phase (continuous phase). Conversion decreases drastically when gas-liquid mass transfer coefficient decreases, which is expected. In addition, as the effect on selectivity of pAP is marginal as none of the reactant transport is occurring between the two liquid phase b. Figure 9 (b) describes the impact of liquid-liquid mass transfer on conversion and selectivity, as described previously there is no impact of L-L mass transfer on the conversion. However, as the value of Da-kla-l decrease beyond a certain limit (Da-kla-1 < 10) the selectivity decreases from 65-70 $\%$ to $20 \%$. The reason behind this is as PHA is continuously being converted to pAP in a relatively fast reaction the impact of LL mass transfer can only be seen at very low values of Da-kla-1.

\subsubsection{Influence of temperature}

Figure 10 and 11 shows the change in conversion of NB at Da-Rxn numbers, which may represent reaction rates at different temperatures. The simulations presented were done at $1 \mathrm{bar}$ hydrogen pressure and $3000 \mathrm{~s}$ residence time. In order to keep the discussion general the DaRxn parameter was varied from 150-450. As shown in Equation (38) the concentration of hydrogen in liquid does change with the change in the mass transfer coefficient and reaction rates. As the rate of reaction increase, mass transfer coefficient must be increased.

$C_{H_{2}}=\left(\frac{k l a}{k l a+k_{R x n} \varepsilon_{L i q}}\right) C_{H_{2}}^{*}$

Figure 10 shows contour plots for conversion vs. Da-Rxn and Da-kla-g at four instances of Dakla-1. As seen from the figure the conversion profiles at lower Da-Rxn and Da-kla-g are similar to each other. Hence, it is to be noted that for Da-Rxn $<225$ and Da-kla-g $<1500$ there is no significant difference between the conversion values for $15000<\mathrm{Da}-\mathrm{kla}-1<300$. However, as the reaction rates increase ( $\mathrm{Da}-\mathrm{Rxn}>250)$ the effects of L-L mass transfer become more and more 
pronounced as we can see that the conversion starts to decrease. Figure 11 shows when reaction phase is continuous $D a_{R x n} / D a_{k l a-g}$ must be less than 0.25 if Da-Rxn $>350$. Also, for Da-Rxn < 200 mass transfer has a relatively low impact on the overall rate of reaction. L-L mass transfer virtually has no impact on the conversion or selectivity if the reaction phase is continuous if Da-kla-1 > 10 .

\subsubsection{Influence of Hold-up of reaction phase}

In this section, the effect of hold up on reaction conditions is studied as the mass transfer requirements change with the change in hold of the reaction phase. If the organic or the reaction phase is dispersed then, the holdup will have impact on gas-liquid transfer requirements. The relationship of conversion of $\mathrm{NB}$ and selectivity to $\mathrm{pAP}$ with the hold up and liquid-liquid mass transfer coefficient can be seen in Figure 12. Where, as $D a_{R x n} / D a_{k l a-l}$ is less than 0.14 then the reaction operates in the kinetically controlled regime for range of hold up considered in the study. For all the simulations varying kla-l, the value of kla-g was kept constant at $D a_{R x n} / D a_{k l a-g}=0.06$.

Figure 13 shows the relation between selectivity and conversion with reaction phase hold up and gas-liquid mass transfer coefficient. The reaction is in surface reaction regime for $D a_{R x n} / D a_{k l a-g}<0.28$ for reaction phase hold up of 0.2 and 0.14 for reaction phase hold up of 0.4. This is simply because it takes more hydrogen to saturate higher volume of reaction phase and more reaction phase volume means higher consumption of hydrogen due to higher overall rate of reaction. Hence, to keep up with this higher mass transfer rates are required. Similar trend is observed for selectivity where higher mass transfer coefficient is required for higher reaction phase hold up to operate the reaction in surface reaction regime. The selectivity starts to get affected only at very low values of kla-g. For a major portion of the values of kla-g the selectivity does not change much but for very low values of kla-g selectivity decreases drastically. All the simulations Da-kla-l was kept constant at $D a_{R x n} / D a_{k l a-l}=0.03$. 
For organic/reaction phase as the continuous phase the plots for conversion and selectivity versus $D a_{R x n} / D a_{k l a-g}$ at different hold up of reaction phase are shown in Figure 14. As can be seen from the figure, higher value of kla-g is required for higher hold up values and vice versa. When the values of $D a_{R x n} / D a_{k l a-g}$ are $<0.06$ we see the kinetically controlled operation for $3000 \mathrm{~s}$ residence time. For all the simulations varying kla-g, the value of kla-l was kept constant at $D a_{R x n} / D a_{k l a-l}=0.06$. As mentioned earlier the effect of L-L mass transfer on conversion of NB also selectivity remains unchanged for Da-kla-1 > 10.

\subsection{Extension to a multi-cell framework}

The discussion presented in the present work is limited to the framework of a single cell or an ideal CSTR. While in small reactors the ideally mixed tank assumption may be valid, but in larger reactors (> 100 lit) the stirred tank assumption breaks down due to improper mixing. In an inadequately mixed system there may separate zones having different degrees of mixing. Such regions may have different values of temperature, catalyst concentration and mass transfer rates. In the above mentioned circumstances the current approach of a single mixed cell will break down. In order to implement the current GLLS reaction modelling approach in a larger system the knowledge of flow regimes and over all flow parameters is required. Computation fluid dynamics (CFD) approach is best suited for analysing situations where flow plays a very important part in governing hydrodynamics and mass transfer. After resolving the flow inside the reactor a multi-zonal model may be developed using the flow profiles inside the reactor. Development of multi-zonal model in a stirred tanks is discussed in Alopaeus et al ${ }^{[34]}$ and Bezzo et al ${ }^{[35]}$.

The sensitivity to Da-kla studies are simplified simulations showing the sensitivity to mass transfer coefficients. The lower mass transfer rate cases may be coupled with change in regime of flow and the mixed flow assumptions will now be valid. However, this is simply an exercise in showing how the rates and conversion will be affected if with the variation of mass transfer coefficient. 


\section{Conclusions}

A classical reaction engineering approach was used to analyse four phase hydrogenation systems incorporating kinetic, thermodynamic and transport parameters. A comprehensive reaction engineering model was developed which included different mass transfer steps, chemical reactions in two immiscible liquid phases and solvent vaporization. The model was first tested by simulating published experimental data on nitrobenzene hydrogenation. The model was shown to capture influence of temperature, pressure and selection of continuous phase on conversion of NB and selectivity towards para amino phenol quite well. The model was used to quantify influence of parameters like pressure, temperature, hold up and mass transfer on conversion and selectivity. The results provided some guidelines for the selection of gas-liquid contactors for conducting four phase reactions. These results indicate the following:

- At $D a_{R x n} / D a_{k l a-l}<0.14$ and $D a_{R x n} / D a_{k l a-g}<0.06$, overall reaction rates are kinetically controlled and maximum selectivity towards pAP was observed at $30 \%$ hold up of reaction phase if dispersed and $70 \%$ hold for continuous phase as the reaction phase.

- For reaction phase as continuous phase $D a_{R x n} / D a_{k l a-g}<0.25$ if Da-Rxn $>350$ for operation in kinetic controlled regime. Whereas, for reaction phase as dispersed if $D a_{R x n} / D a_{k l a-g}<0.15$ the overall rate is in kinetically controlled regime at all the values of Da_kla-1.

- Addition of solvent like hexane drastically improves the hydrogen solubility. The saturated hydrogen concentration in a 1:1 :: Hexane : NB (mass ratio) mixture at 1 bar (hydrogen pressure) is equivalent to concentration of hydrogen in NB at 2.5 bar.

- G-L mass transfer has a deep impact on the conversion of NB when the organic phase is continuous, $D a_{R x n} / D a_{k l a-g}$ should be less than 0.06 for operation is kinetic controlled regime. At the same time L-L mass transfer has virtually no effect on conversion and selectivity for Da-kla-1 > 10.

- Both G-L and L-L mass transfer have an impact on selectivity and conversion when reaction phase is dispersed $D a_{R x n} / D a_{k l a-g}$ and $D a_{R x n} / D a_{k l a-l}$ should be less than 0.28 and 0.14 for operation in kinetic controlled regime. 


\section{Associated Content}

\section{Supporting Information}

The Supporting Information is available free of charge on the ACS Publications website http://pubs.acs.org.

Additional details pertaining to derivation of the model equations in their conservative form and details for solution initialization are provided in Appendix 1 of this document. Experimental procedure and relevant data are included in Appendix 2.

\section{Acknowledgement}

Deepankar V Sharma acknowledges Council for Scientific and Industrial Research (CSIR) for Senior Research Fellowship. Authors also gratefully acknowledge useful contributions of Dr C.V. Rode, Dr. Sunil Joshi and Mr Nandan Date towards this work. 
Notations

\begin{tabular}{|c|c|c|c|}
\hline $\mathrm{Sr} \#$ & Quantity & Symbol & Unit \\
\hline 1 & Area & $A c$ & $\mathrm{~m}^{2}$ \\
\hline 2 & Concentration & $C$ & $\mathrm{kmol} / \mathrm{m}^{3}$ \\
\hline 3 & Density & $\rho$ & $\mathrm{Kg} / \mathrm{m}^{3}$ \\
\hline 4 & Enthalpy & $h$ & $\mathrm{~kJ}$ \\
\hline 5 & Fugacity & $f$ & \\
\hline 6 & Hold up & $\varepsilon$ & \\
\hline 7 & Mass flow rate & $\dot{m}$ & $\mathrm{Kg} / \mathrm{s}$ \\
\hline 8 & Mass fraction & $x$ & \\
\hline 9 & Mole Fraction & $\theta$ & \\
\hline 10 & Molecular weight & $M w$ & $\mathrm{~kg} / \mathrm{kmol}$ \\
\hline 11 & Order of reaction & $\mathrm{O}$ & \\
\hline 12 & Pressure & $P$ & $\mathrm{~Pa}$ \\
\hline 13 & $\begin{array}{c}\text { Rate of mass } \\
\text { transfer }\end{array}$ & $S$ & $\mathrm{kmol} / \mathrm{m}^{3} \mathrm{~s}$ \\
\hline 14 & Rate of reaction & $R$ & $\mathrm{kmol} / \mathrm{m}^{3} \mathrm{~s}$ \\
\hline 15 & Recirculation rate & $F$ & $\mathrm{~m}^{3} / \mathrm{s}$ \\
\hline 16 & Stoichiometry & $A$ & \\
\hline 17 & Temperature & $T$ & $\mathrm{~K}$ \\
\hline 18 & time & $t$ & $\mathrm{~S}$ \\
\hline 19 & Transfer coefficient & $k_{P Q}$ & $(1 / s)$ \\
\hline 20 & Volume & $V$ & $\mathrm{~m}^{3}$ \\
\hline 21 & Specific Heat & $C p$ & $\mathrm{~kJ} /(\mathrm{kg} . \mathrm{K})$ \\
\hline 22 & Latent Heat & $\lambda$ & $\mathrm{kJ} / \mathrm{kg}$ \\
\hline 23 & Heat of reaction & $\Delta H$ & $\mathrm{~kJ} / \mathrm{kmol}$ \\
\hline 24 & $\begin{array}{c}\text { Universal Gas } \\
\text { Constant }\end{array}$ & $\mathrm{R}$ & $\mathrm{kJ} /(\mathrm{kmol} . \mathrm{K})$ \\
\hline
\end{tabular}


Subscripts/ Superscripts

$\begin{array}{ccc}\text { Sr \# } & \text { Symbol } & \text { Symbol } \\ 1 & \text { Reactor cell n } & n \\ 2 & \text { species } & i \\ 3 & \text { Dispersion } & D \\ 4 & \text { Phase } & P \\ 5 & \text { Reaction number } & k \\ 6 & \text { Gas phase } & g \\ 7 & \text { Over head space } & \text { OH } \\ 8 & \text { No. of phases } & Z \\ 9 & \text { reference } & r e f \\ 10 & \text { Number of species } & N \\ 11 & \text { Number of reactions } & M \\ 12 & \text { Reactor } & R \\ 13 & \text { Coming in/going } & \text { in } / o u t\end{array}$




\section{References}

1. Struijk, J.; d'Angermond, M.; Lucas-de-Regt. W.J.M.; Scholten, J.J.F. Partial liquid phase hydrogenation of benzene to cyclohexene over ruthenium catalysts in the presence of an aqueous salt solution. App. Cat. A: Gen. 1992, 82, 263.

2. Turakova, M.; Salmi, T.; Eranenc, K.; Warnac, J.; Murzinc, D.Y.; Kralika, M. Liquid Phase Hydrogenation of Nitrobenzene. App. Cat. A: Gen. 2016, 499, 66.

3. Pangarkar, V.G. Design of Multiphase Reactors, $1^{\text {st }}$ Edition; John Wiley and Sons: Hoboken, New Jersey, 2015; pp 429.

4. Yamada, H.; Urano, H.; Goto, S. Selective Hydrogenation of unsaturated aldehyde in gas-liquid-liquid-solid four phase. Chem. Eng. Sci. 1999, 54(21), 5231.

5. Garf, I.; Landenburger, G.; Kraushaar-Czarnetzki, B. Heat Transport in catalytic sponde packings in the presence of an exothermal reaction: Characterization by 2D modelling of experiments. Chem. Eng. J. 2016, 287, 425.

6. Liu, H.; Fang. R.; Li. Z.; L, Y. Solvent less hydrogenation of benzene to cyclohexane over a heterogeneous Ru-Pt bimetallic catalyst. Chem. Eng. Sci. 2015, 122, 350.

7. Lehtonen, J.; Slami, T.; Vuori, A.; Tirronen, E. On the Principles of Modelling of Homogeneous-Heterogeneous Reactions in the Production of Fine Chemicals. A Case Study: Reductive Alkylation of Aromatic Amines. Org. Process Res. Dev. 1998, 2, 78.

8. Roy, D.; Chaudhary, R.V. Analysis of a Gas-Liquid-Liquid-Solid Catalytic Reaction: Kinetics and Modeling of a Semibatch Slurry Reactor. Ind. Eng. Chem. Res. 2005, 44, 9586.

9. Rode, C. V.; Vaidya, R.; Chaudhari, R. V. Synthesis of p-Aminophenol by Catalytic Hydrogenation of Nitrobenzene. Org. Process Res. Dev. 1999, 3, 465.

10. Li, G.; Ma, J.; Pengi, X.; L. C. Kinetics Approach for Hydrogenation of Nitrobenzene to p-Aminophenol in a Four-Phase System. Asian J. Chem. 2011, 23, 1001.

11. Lekhar, A.; Chaudhary, R.V.; Wilhelm, A.M.; Delmas, H. Gas-Liquid mass transfer in gas-liquid-liquid dispersions. Chem. Eng. Sci. 1997, 52, 4069. 
12. Yamada, H.; Tagawa, T.; \& Goto, S. Hydrogenolysis for deprotection of aminoacid in a stirred tank reactor containing gas-liquid-solid four phases. J. Chem. Eng. Japan. 1996, 29(2), 373.

13. Rode, C. V.; Vaidya, M. J.; Jaganathan, R.; Chaudhari, R. V. Hydrogenation of nitrobenzene to $\mathrm{p}$-aminophenol in a four-phase reactor: reaction kinetics and mass transfer effects. Chem. Eng. Sci. 2001, 56, 1299.

14. Jiang, H.; Yan, Q.; Du, Y.; Chen, R. Synthesis of p-Aminophenol from p-Nitrophenol Reduction over Pd@ZIF-8. React. Kinet.Mech. Cat. 2016, 117, 307.

15. Henke, C. O. \& Vaughan, J. V. Reduction of aryl nitro compounds. US patent 2,198,249. 1940.

16. Dong, Z.; Wang, T.; Zhao, J.; Fu, T.; Guo, X.; Peng, L.; Zhao, B.; Xue, N.; Ding, W.; Xie, Z. Ni-Silicides Nanoparticles as Substitute for Nobel Metals for Hydrogenation of Nitrobenzene to p-Aminophenol in Sulphuric Acid. App. Cat. A. 2016, 520, 151.

17. Wang, T.; Dong, Z.; Fu, T.; Zhao, T.; Wang, T.; Wang, Y.; Chen, Y.; Han, B.; Ding, W. Nickel Embedded in N-doped Porous Carbon for Hydrogenation of Nitrobenzene to p-Aminophenol in Sulphuric Acid. Chem. Comm. 2015, 51, 17712.

18. Scovazzo, P.; Camper, D.; Keift, J.; Poshusta, J.; Koval, C.; Noble, R. Regular Solution Theory and CO2 Gas Solubility in Room-Temperature Ionic Liquids. Ind. Eng. Chem. Res. 2004, 43, 6855.

19. Burnner, E. Solubility of Hydrogen in 10 Solvents at 298.15, 323.15 and 373.15 K. J. Chem. Eng. 1958, 30, 289.

20. Radhakrishnan, K.; Ramachandran, P.A.; Brahme, P.H.; Chaudhari, R.V. Solubility of Hydrogen in Methanol, Nitrobenzene, and Their Mixtures. Experimental Data and Correlations. J. Chem. Eng. Data. 1983, 23, 339.

21. Somersen, J.; Arlt, W. Liquid-liquid Equilibrium Data Coll. (Binary systems), 1981. DECHEMA Chem. Data Ser. Vol. V, Part 1.

22. Shampine, L. F. and Reichelt, M.W. The MATLAB ODE Suite, SIAM J. Sci. Computing. 1997, Vol. 18, pp 1-22. 
23. Vaidya, M.J. "Catalysis and Kinetics of Hydrogenation of Nitrobenzene to pAminophenol", Ph. D. Thesis, University of Pune, Pune, India, 2002.

24. IUPAC-NIST Solubility Data Series. Hydrocarbons with Water and Seawater-Revised and Updated. Part 5. C7 Hydrocarbons with Water and Heavy Water; J. Phys. Chem. 2005, Ref. Data, Vol. 34, No. 3, 81.

25. Yamada, H.; Tagawa, T.; \& Goto, S. Hydrogenolysis for deprotection of aminoacid in a stirred tank reactor containing gas-liquid-solid four phases. J. Chem. Eng. Japan. 1996, 29(2), 373.

26. Rode, C.V.; Date, N. Synthesis of p-Aminophenol from Nitrobenzene. CSIR - National Chemical Laboratory Internal Report. 2015.

27. Spod, H.; Lucas, M.; Claus, P. Continuously Conducted Hydrogenation of Benzene to Cyclohexene. Chem. Eng. Tech. 2015, 38. 239.

28. Muller, A.; Ludwig, M.; Arlit, M.; Lange, R. Evaluation of reactor concepts for the continuous production of fine chemicals using the selective hydrogenation of cinnamaldehyde over palladium catalysts. Catal. Today. 2015, 241 (B), 214.

29. Joshi, J. B.; Pandit A. B.; Sharma, M. M. Mechanically Agitated Gas-Liquid Reactors. Chem. Eng. Sci. 1982, 37, 813.

30. Patwardhan, A.W.; Joshi, J.B. Design of Stirred Vessels with Gas Entrained from Free Liquid Surface. Can. J. Chem. Eng. 1998, 76, 339.

31. Simnick, J.j.; Sebastian, H.M.; Lin, H.; Chao, K. Solubility of Hydrogen in Toluene at Elevated Temperatures and Pressures. J. Chem. Eng. Data. 1978, 23, 339.

32. Chaudhari, R. V.; Gholap, R. V.; Emig, G.; \& Hofman, H. Gas-liquid mass transfer in dead end autoclave. Can. J. Chem. Eng. 1987, 65, 744.

33. Chardhari, A.S.; Rampure, M.R.; Ranade, V.V.; Jaganathan, R.; Chaudhari, R.V. Modeling of bubble column slurry reactor for reductive alkylation of pphenylenediamine. Chem. Eng. Sci. 2007, 62, 7290. 
34. Alopaeus, V.; Moilanen, P.; Laakkonen, M. Analysis of stirred tanks with two zones model. AIChE. 2009, 55, 2545.

35. Bezzo, F.; Macchietto, S. A general methodology for hybrid multizonal/CFD models: Part II. Automatic zoning. Computers Chem. Eng. 2004, 28, 513. 


\section{List of Tables:}

Table 1: Examples of four phase reaction systems

Table 2: Examples for hydrogenation of nitrobenzene

\section{List of Figures:}

Figure 1: Detailed reaction scheme of hydrogenation of NB to pAP using Pt/C catalyst Figure 2: Schematic representative of a single cell of GLLS reactor model

Figure 3: Kinetics fitting for GLLS model using data from Vaidya et al at Pressure $2.72 \mathrm{MPa}$

Figure 4: Comparison of experimental from Vaidya et al ${ }^{[23]}$ and simulated results using the fitted kinetics for (a) hydrogen consumption and (b) selectivity of pAP at Temperatures 323$353 \mathrm{~K}$ and Pressure 0.68-6.8 MPa

Figure 5: Fitting of kinetics using experimental data for (a) Hydrogen Consumption and (b) Temperature using GLLS model

Figure 6: Comparison of Single phase, 3 phase and 4 phase (GLLS) model (dispersed reaction phase) results and experimental results for different values of (a) G-L and (b) L-L mass transfer coefficients

Figure 7 Experimental vapour pressure of the reaction mixture against the NRTL model predictions

Figure 8: Effect of Gas-Liquid and Liquid-Liquid Mass transfer on (a) Conversion of NB and (b) Selectivity towards pAP at 30\% Reaction Phase Hold up (dispersed)

Figure 9: Effect of Gas-Liquid and Liquid-Liquid Mass transfer on (a) Conversion of NB and (b) Selectivity towards pAP at $70 \%$ Reaction Phase Hold up (Continuous)

Figure 10: Effect on Conversion at different Reaction Damkholer Number (Da-Rxn), G-L and L-L Mass Transfer Damkholer Number (Da-kla-g \% Da-kla-l) for Dispersed Reaction Phase (30\% hold up) 
Figure 11: Effect on Conversion at different Reaction Damkholer Number (Da-Rxn), G-L Mass Transfer Damkholer Number (Da-kla-g) for Continuous Reaction Phase (70\% hold up)

Figure 12: Effect of Dispersed Reaction Phase Holdup and Liquid-Liquid Mass transfer on Conversion of NB

Figure 13: Effect of Dispersed Reaction Phase Holdup and Gas -Liquid Mass transfer on (a) Conversion of NB and (b) Selectivity towards pAP, Da_Rxn/Da_kla_1 $=0.06$

Figure 14: Effect of Continuous Reaction Phase Holdup and Liquid-Liquid Mass transfer on Conversion of NB 
Table 1 Examples of four phase reaction systems

\begin{tabular}{|c|c|c|c|c|c|}
\hline System & Reference & $\begin{array}{l}\text { Operating } \\
\text { conditions }\end{array}$ & $\begin{array}{l}\text { Reactor } \\
\text { type/ } \\
\text { presented } \\
\text { data }\end{array}$ & $\begin{array}{c}\text { Models } \\
\text { used }\end{array}$ & Remark \\
\hline $\begin{array}{l}\text { Hydrogenation of } \\
\text { Benzene }\end{array}$ & $\begin{array}{l}\text { Garf et al } \\
(2016)\end{array}$ & $\begin{array}{c}170-210^{\circ} \mathrm{C} \\
6 \mathrm{bar}\end{array}$ & $\begin{array}{c}\text { Continuous, } \\
\text { packed bed, } \\
\text { sponge } \\
\text { catalyst }\end{array}$ & $\begin{array}{c}\text { Axial } \\
\text { dispersion } \\
\text { model, } \\
\text { Single } \\
\text { phase }\end{array}$ & $\begin{array}{c}\text { Heat } \\
\text { condition } \\
\text { in packed } \\
\text { bed }\end{array}$ \\
\hline $\begin{array}{l}\text { Hydrogenation of } \\
\text { Benene to } \\
\text { cyclohexene }\end{array}$ & $\begin{array}{c}\text { Spod et } \\
\mathrm{al}^{[27]}(2015)\end{array}$ & $\begin{array}{c}150^{\circ} \mathrm{C}, 50 \\
\text { bar }\end{array}$ & $\begin{array}{l}\text { Continuous, } \\
\text { stirred tank, } \\
\mathrm{Ru} / \mathrm{A} 12 \mathrm{O} 3, \mathrm{Zr} \\
\text { O2 }\end{array}$ & None & $\begin{array}{c}\text { Experiment } \\
\text { al work for } \\
\text { stabilizing } \\
\text { continuous } \\
\text { systems }\end{array}$ \\
\hline $\begin{array}{l}\text { Hydrogenation of } \\
\text { Cinnamaldehyde }\end{array}$ & $\begin{array}{c}\text { Muller et } \\
\mathrm{al}^{[28]}(2015)\end{array}$ & $\begin{array}{c}80^{\circ} \mathrm{C}, 10-30 \\
\text { bar }\end{array}$ & $\begin{array}{l}\text { Continuous, } \\
\text { Pellet String } \\
\text { Reactor }\end{array}$ & None & $\begin{array}{l}\text { Isothermal } \\
\text { operation }\end{array}$ \\
\hline $\begin{array}{l}\text { Hydrogenation of } \\
\text { Nitronenzene to } \\
\text { p-Aminophenol }\end{array}$ & $\begin{array}{l}\text { Li et al } \\
(2010)\end{array}$ & - & $\begin{array}{c}\text { Batch, Stirred } \\
\text { tank }\end{array}$ & $\begin{array}{l}\text { Single - } \\
\text { phase } \\
\text { reaction }\end{array}$ & - \\
\hline $\begin{array}{l}\text { Hydrogenation of } \\
\text { Aniline to } \\
\text { cyclohexylamine }\end{array}$ & $\begin{array}{l}\text { Roy et al } \\
(2005)\end{array}$ & $\begin{array}{c}105-145^{\circ}, 10 \\
\text { bar }\end{array}$ & $\begin{array}{c}\text { Batch, Stirred } \\
\text { tank }\end{array}$ & $\begin{array}{l}\text { Single - } \\
\text { phase } \\
\text { reaction }\end{array}$ & $\begin{array}{c}\text { Reaction } \\
\text { engineering } \\
\text { modelling } \\
\text { and kinetic } \\
\text { fitting }\end{array}$ \\
\hline $\begin{array}{l}\text { Hydrogenation of } \\
\text { Nitrobenzene to } \\
\text { p-Aminophenol }\end{array}$ & $\begin{array}{l}\text { Rode et al } \\
\text { (1999) }\end{array}$ & $\begin{array}{c}80^{\circ} \mathrm{C}, 6.8- \\
68 \text { bar }\end{array}$ & $\begin{array}{c}\text { Batch, Stirred } \\
\text { tank, Pt/C }\end{array}$ & None & $\begin{array}{c}\text { Mass } \\
\text { transfer } \\
\text { limiting } \\
\text { regime }\end{array}$ \\
\hline $\begin{array}{c}\text { Reductive } \\
\text { Alkylation of } \\
\text { Aromatic Amines }\end{array}$ & $\begin{array}{l}\text { Lehtonen et } \\
\text { al (1998) }\end{array}$ & $\begin{array}{c}30-75^{\circ} \mathrm{C}, 15 \\
\text { bar }\end{array}$ & $\begin{array}{l}\text { Batch, Stirred } \\
\text { tank }\end{array}$ & $\begin{array}{l}\text { Two phase } \\
\text { reaction }\end{array}$ & $\begin{array}{l}\text { Kinetic } \\
\text { Fitting }\end{array}$ \\
\hline $\begin{array}{l}\text { Hydrogenation of } \\
\text { Cinnamaldehyde }\end{array}$ & $\begin{array}{l}\text { Yamata et } \\
\text { al (1999) }\end{array}$ & $50^{\circ} \mathrm{C}, 1 \mathrm{bar}$ & stirred Tank & None & - \\
\hline $\begin{array}{l}\text { Mass transfer in } \\
\text { gas-liquid-liquid } \\
\text { systems }\end{array}$ & $\begin{array}{l}\text { Lekhal et al } \\
\text { (1997) }\end{array}$ & $30^{\circ} \mathrm{C}, 15$ bar & Stirred Tank & $\begin{array}{c}\text { Surface } \\
\text { Renewal } \\
\text { Theory }\end{array}$ & $\begin{array}{c}\text { Mass } \\
\text { transfer } \\
\text { analysis }\end{array}$ \\
\hline
\end{tabular}


Table 2 Examples for hydrogenation of nitrobenzene

\begin{tabular}{|c|c|c|c|}
\hline System & Reference & $\begin{array}{l}\text { Operating } \\
\text { conditions }\end{array}$ & Catalyst \\
\hline $\begin{array}{l}\text { Hydrogenation of } \\
\text { NB to pAP }\end{array}$ & Dong et al (2016) & $50-80^{\circ} \mathrm{C}, 10-28$ bar & $\begin{array}{c}\text { Ni-Silicides } \\
\text { Nanoparticles }\end{array}$ \\
\hline $\begin{array}{l}\text { Hydrogenation of } \\
\text { NB to pAP }\end{array}$ & Wang et al (2015) & $100-140^{\circ} \mathrm{C}, 10 \mathrm{bar}$ & $\begin{array}{c}\text { Ni doped porous } \\
\text { carbon }\end{array}$ \\
\hline $\begin{array}{c}\text { Hydrogenation of } \\
\text { NB to p-AP }\end{array}$ & Rode et al (2001) & $80^{\circ} \mathrm{C}, 6.8-68$ bar & $\mathrm{Pt} / \mathrm{C}$ \\
\hline $\begin{array}{l}\text { pAP from } \mathrm{p}- \\
\text { Nitrophenol }\end{array}$ & Jiang et al (2016) & $30^{\circ} \mathrm{C}$ & $\mathrm{Pd} / \mathrm{ZIF}-8$ \\
\hline $\begin{array}{l}\text { pAP from p- } \\
\text { Nitrophenol }\end{array}$ & Krishna et al (2014) & - & $\begin{array}{c}\mathrm{Ag} / \mathrm{Co} / \mathrm{RGO} \\
\text { nanocomposite }\end{array}$ \\
\hline $\begin{array}{l}\text { Hydrogenation of } \\
\text { Nitrobenzene }\end{array}$ & $\begin{array}{l}\text { Turakova et al } \\
\text { (2015) }\end{array}$ & $30-70^{\circ} \mathrm{C}, 20$ bar & $\mathrm{Pd} / \mathrm{C}$ \\
\hline
\end{tabular}




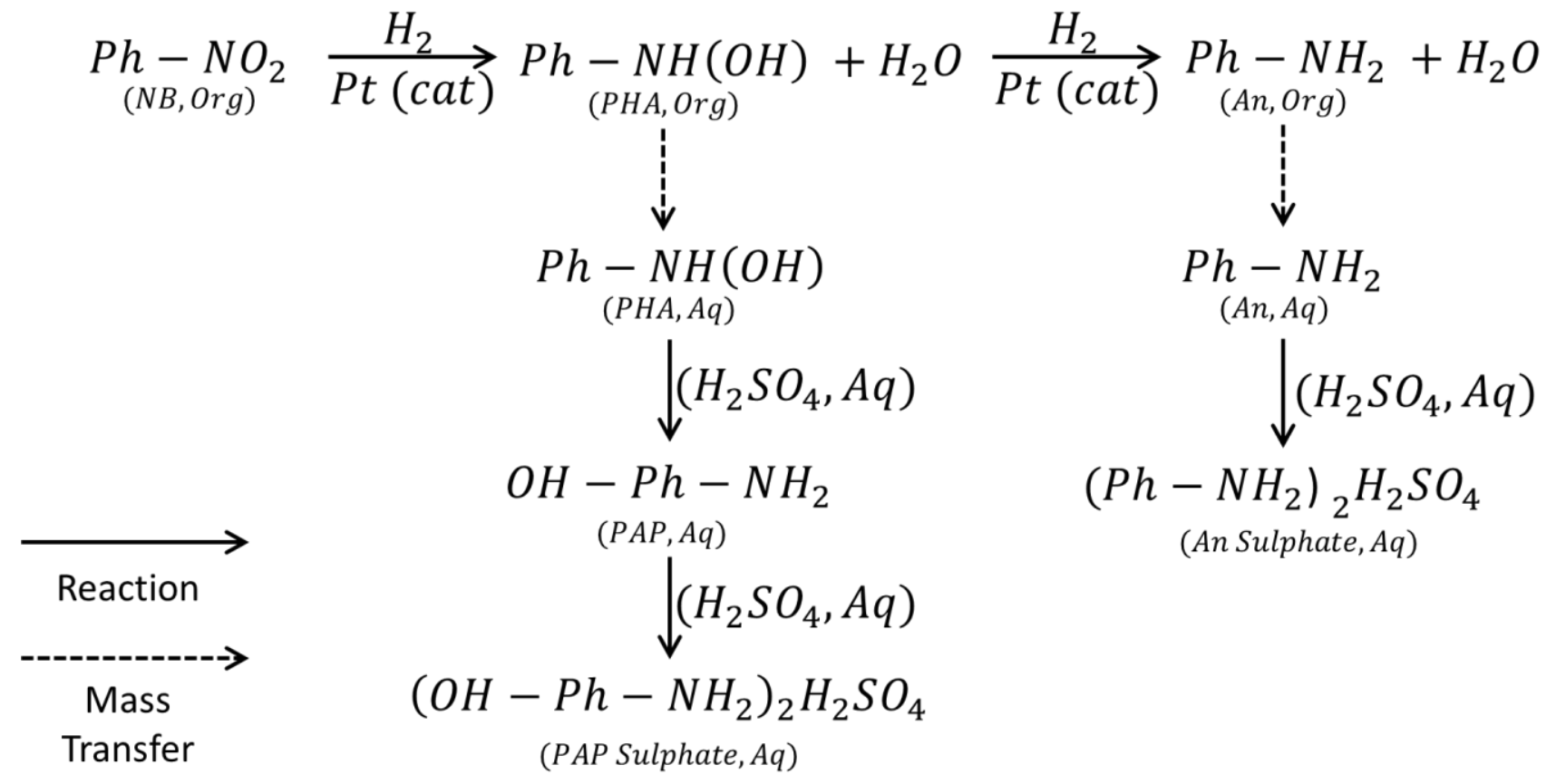

Figure 1: Detailed reaction scheme of hydrogenation of NB to pAP using Pt/C catalyst 


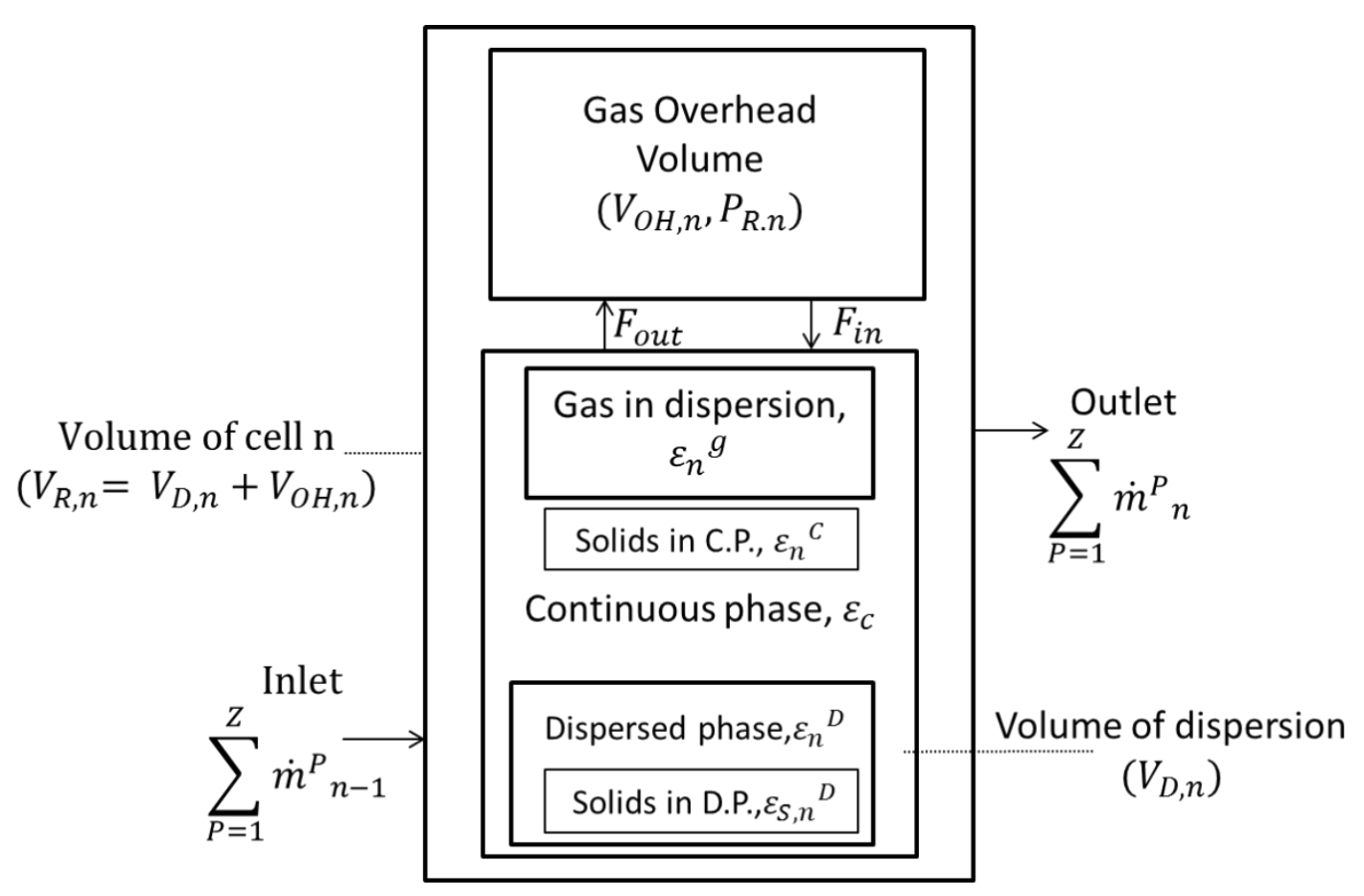

Figure 2: Schematic representative of a single cell of GLLS reactor model 


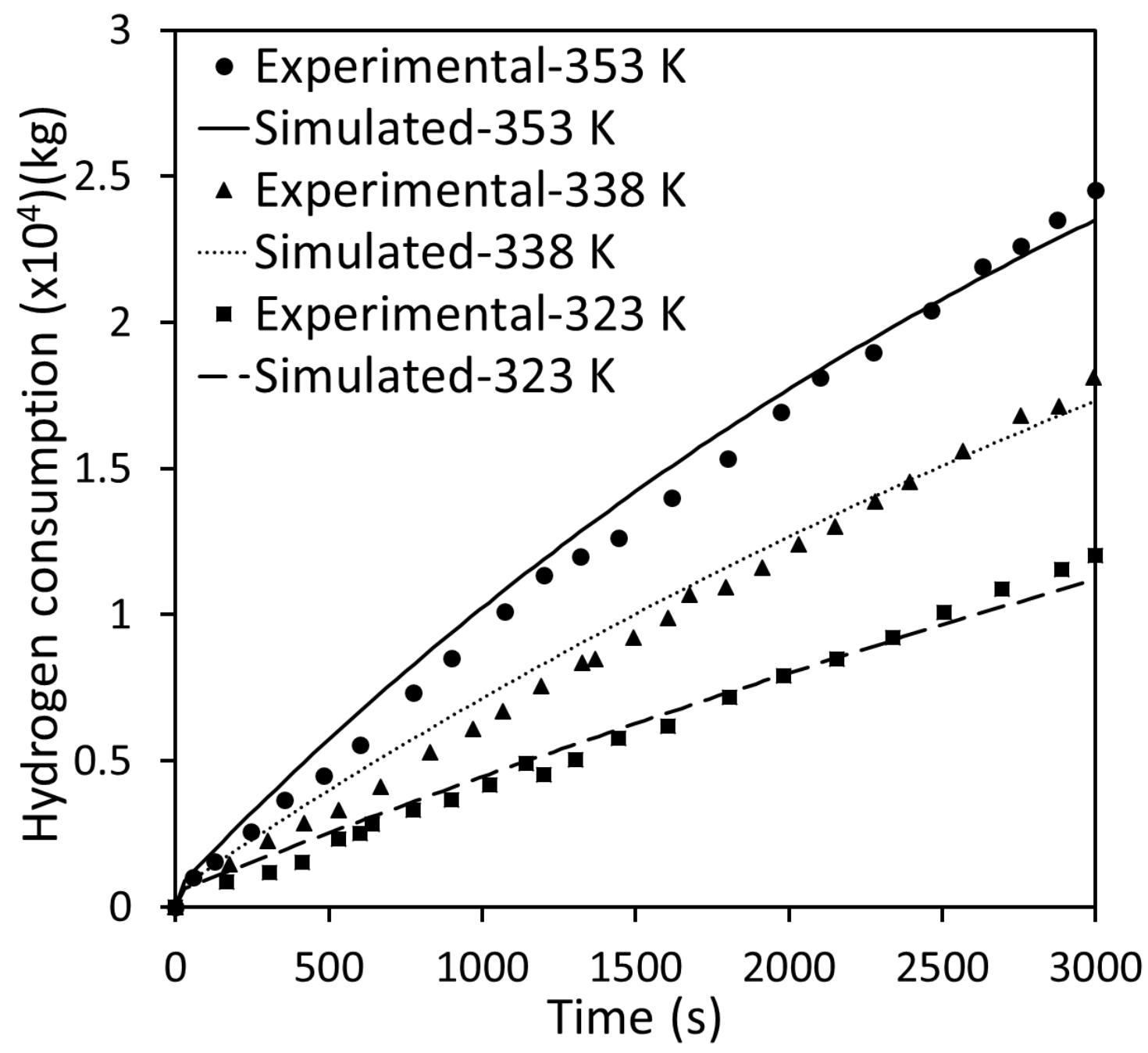

Figure 3: Kinetics fitting using GLLS model using data from Vaidya et al at Pressure 2.72 $\mathrm{MPa}$ 


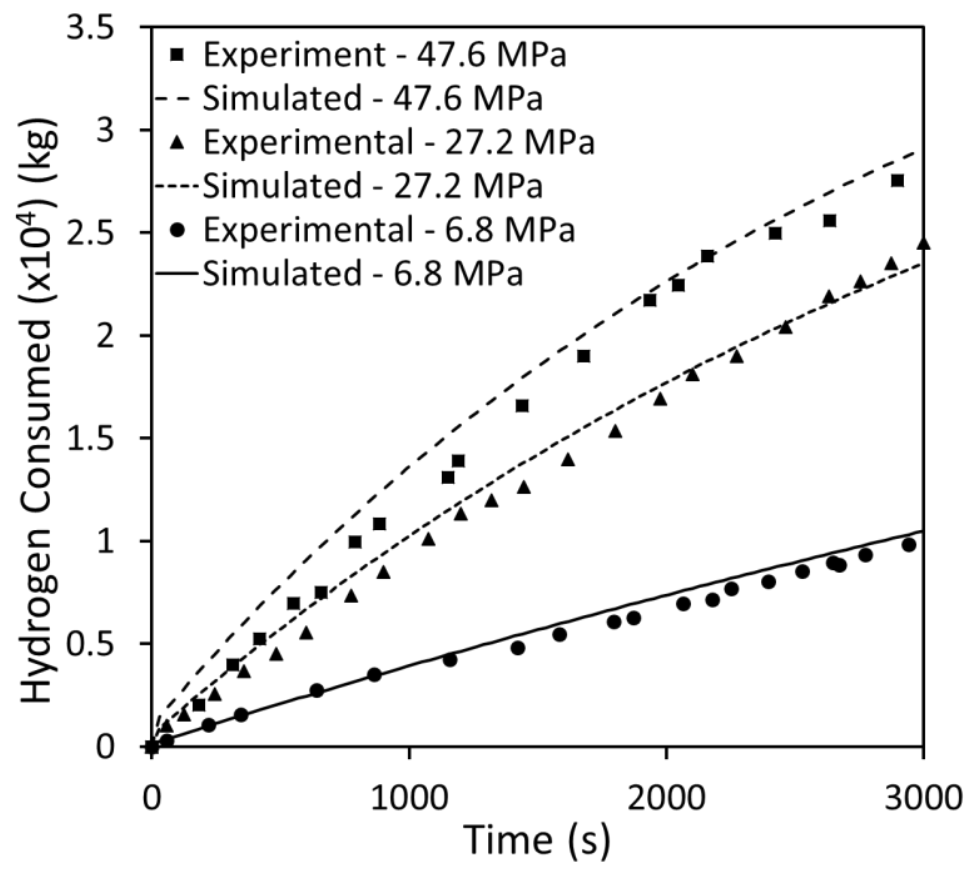

Figure 4 (a)

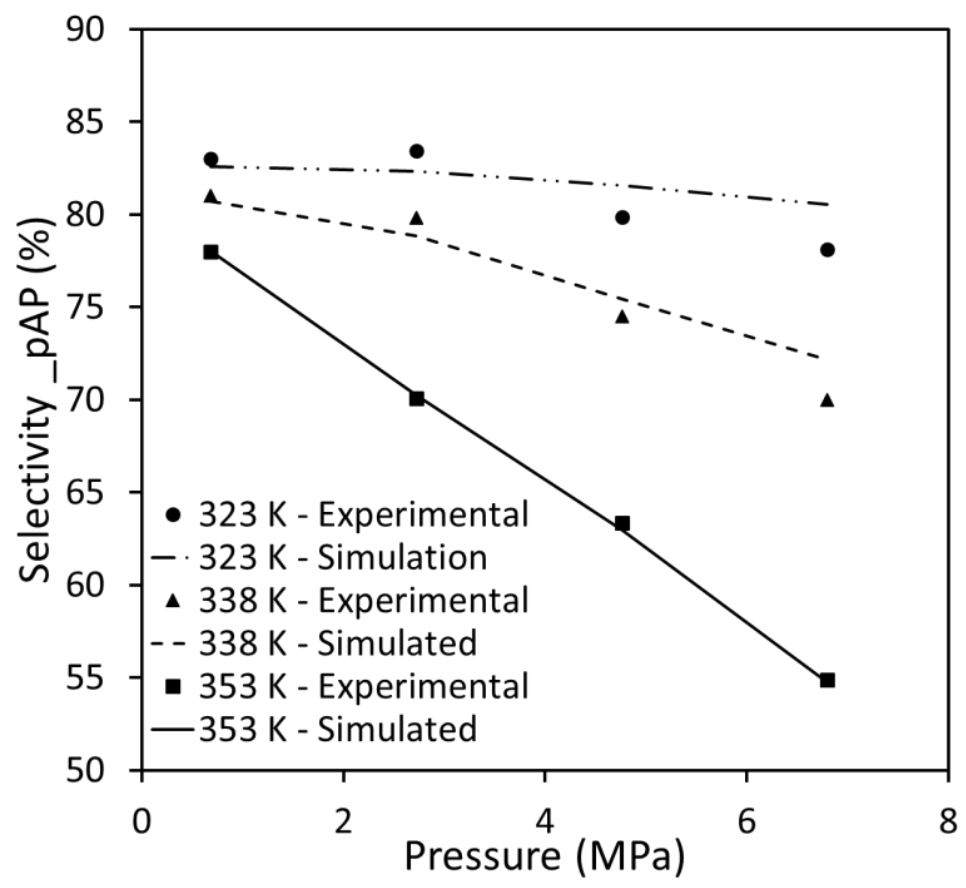

Figure 4 (b)

Figure 4: Comparison of experimental from Vaidya et al ${ }^{[23]}$ and simulated results using the fitted kinetics for (a) hydrogen consumption and (b) selectivity of pAP at Temperatures 323$353 \mathrm{~K}$ and Pressure 0.68-6.8 MPa 


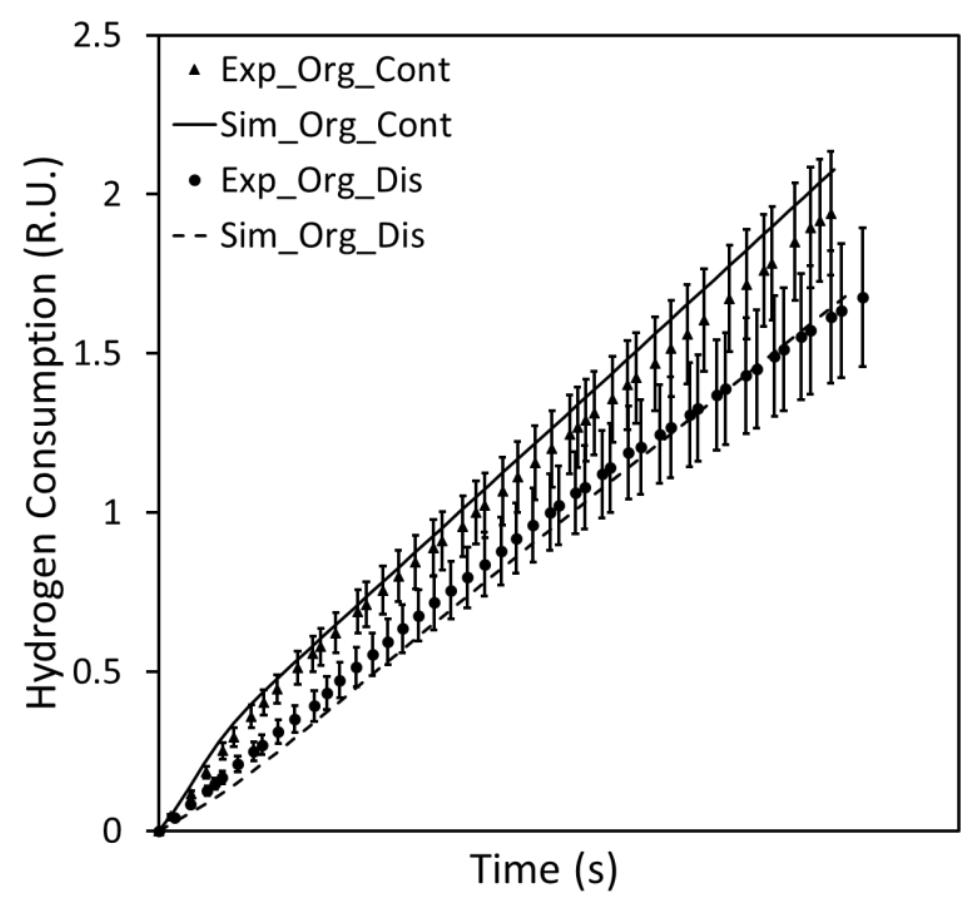

(a)

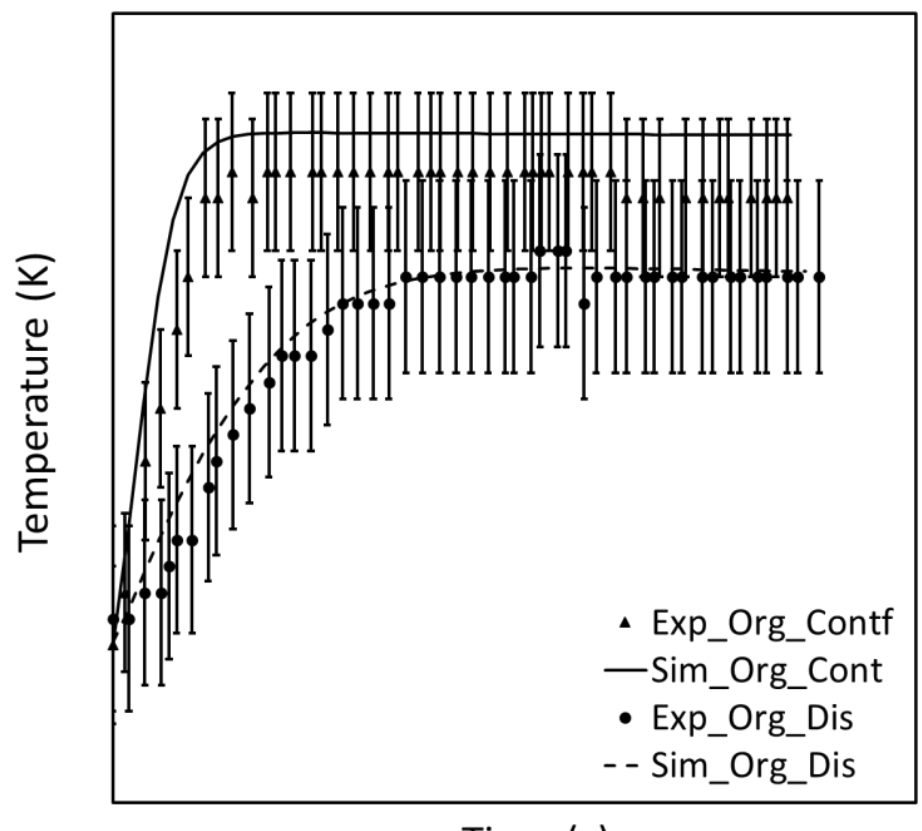

Time (s)

(b)

Figure 5: Fitting of kinetics using experimental data for (a) Hydrogen Consumption and (b) Temperature using GLLS model 


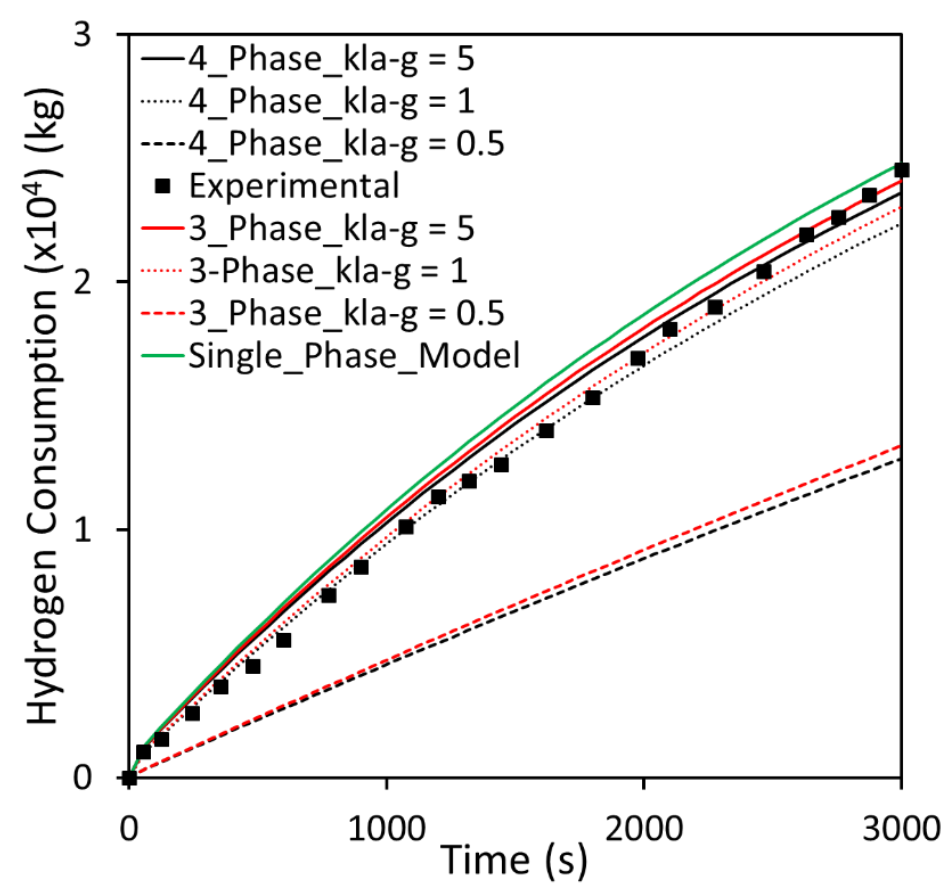

(a)

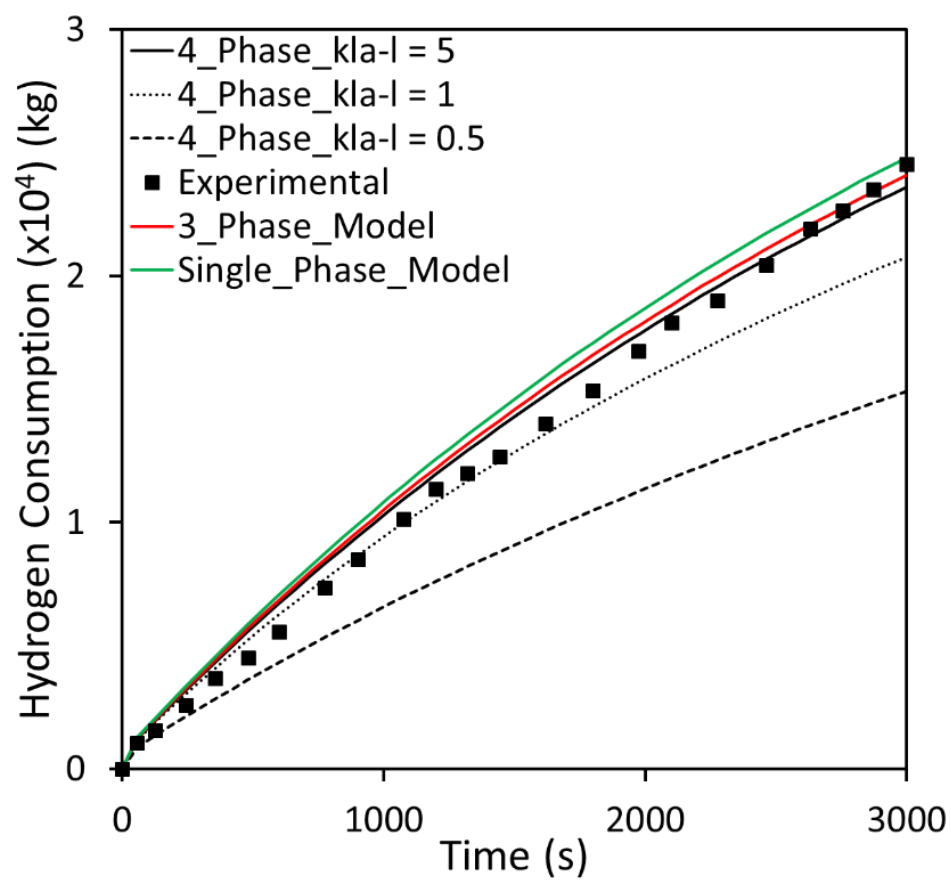

(b)

Figure 6: Comparison of Single phase, 3 phase and 4 phase (GLLS) model (dispersed reaction phase) results and experimental results for different values of (a) G-L and (b) L-L mass transfer coefficients 


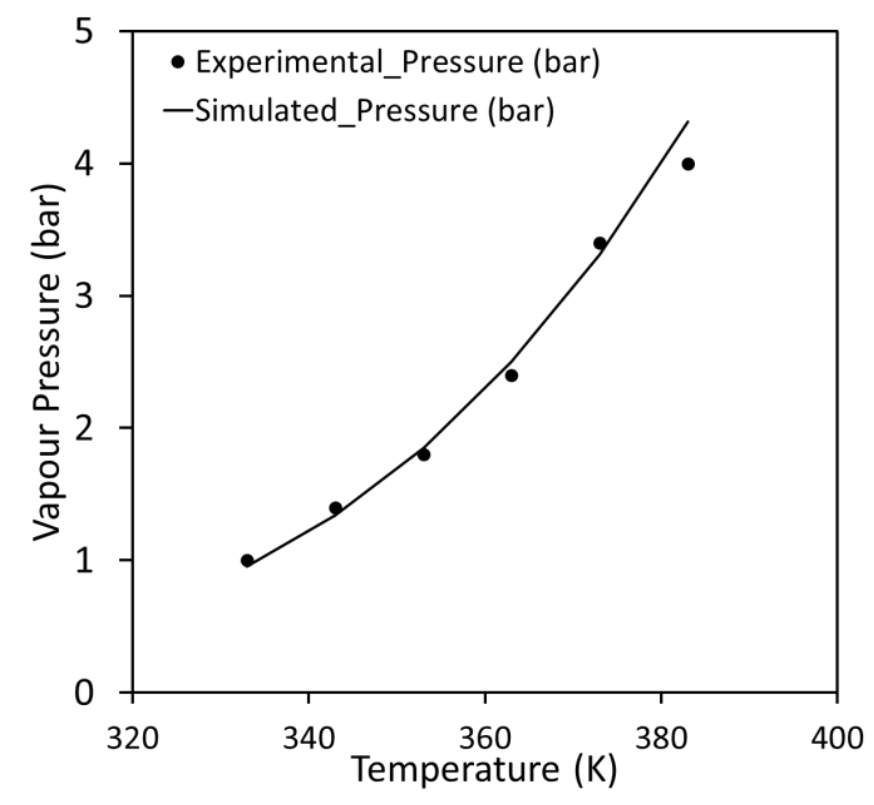

Figure 7 Experimental vapour pressure of the reaction mixture against the NRTL model predictions 


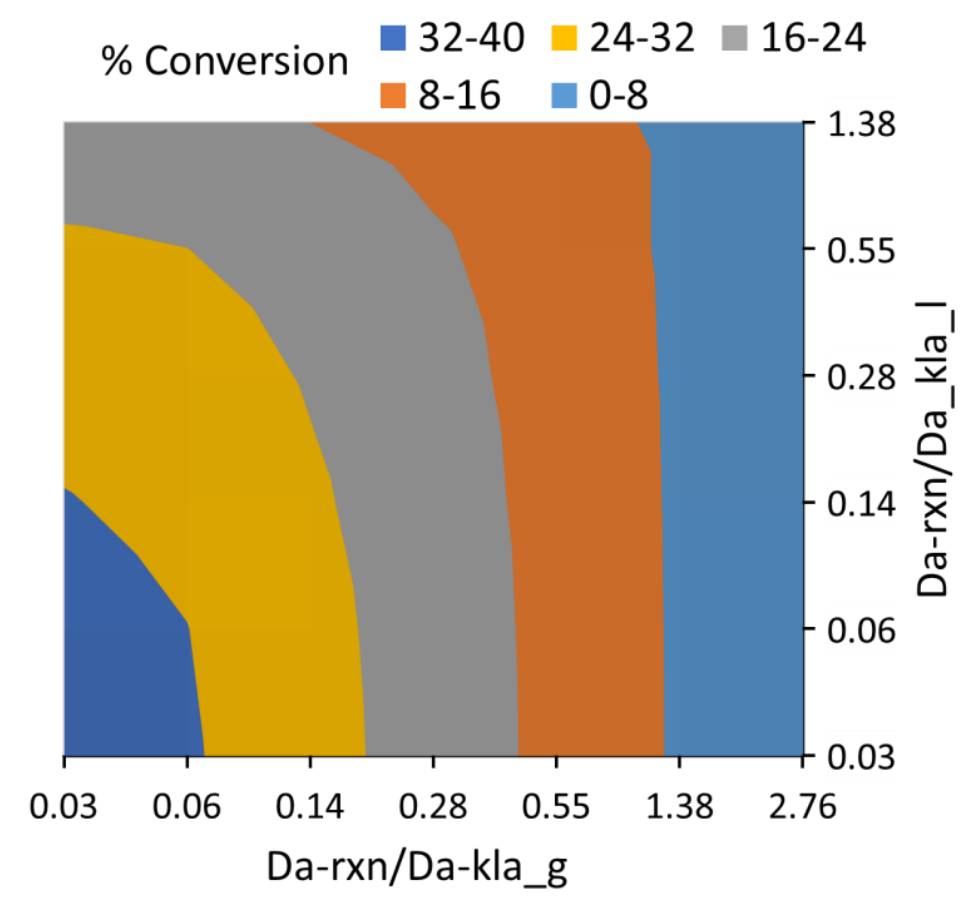

(a)

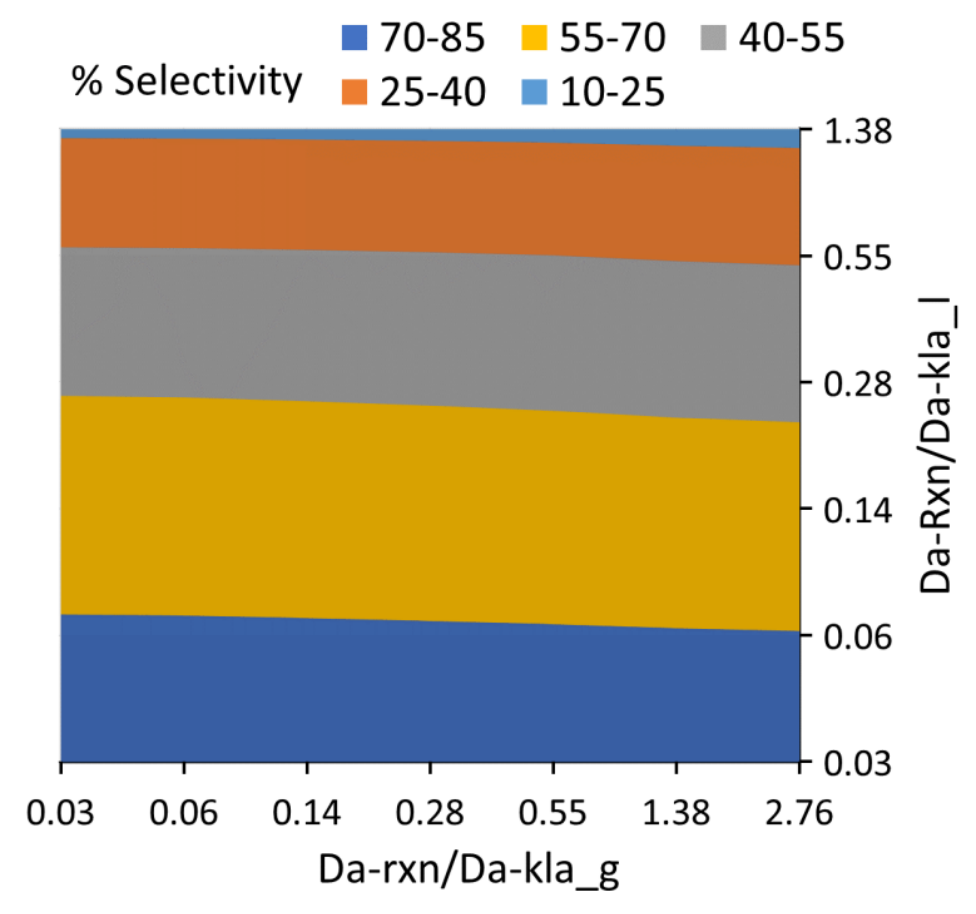

(b)

Figure 8: Effect of Gas-Liquid and Liquid-Liquid Mass transfer on (a) Conversion of NB and (b) Selectivity towards pAP at 30\% Reaction Phase Hold up (dispersed) 


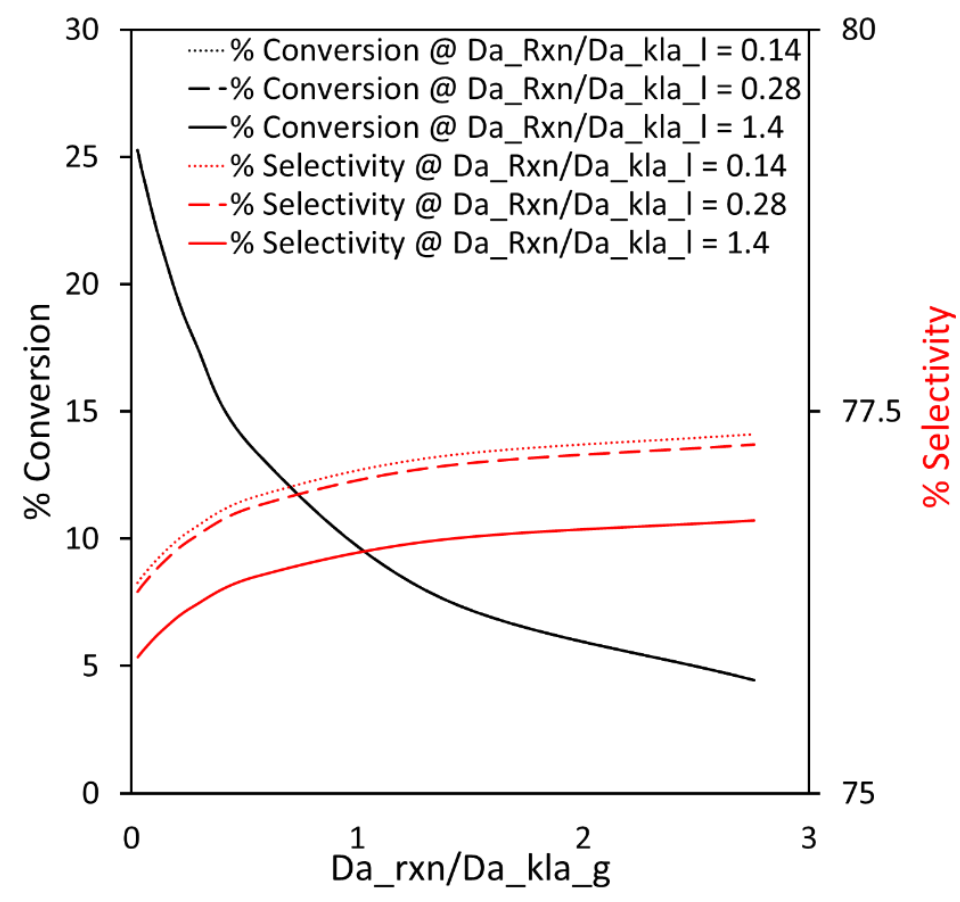

(a)

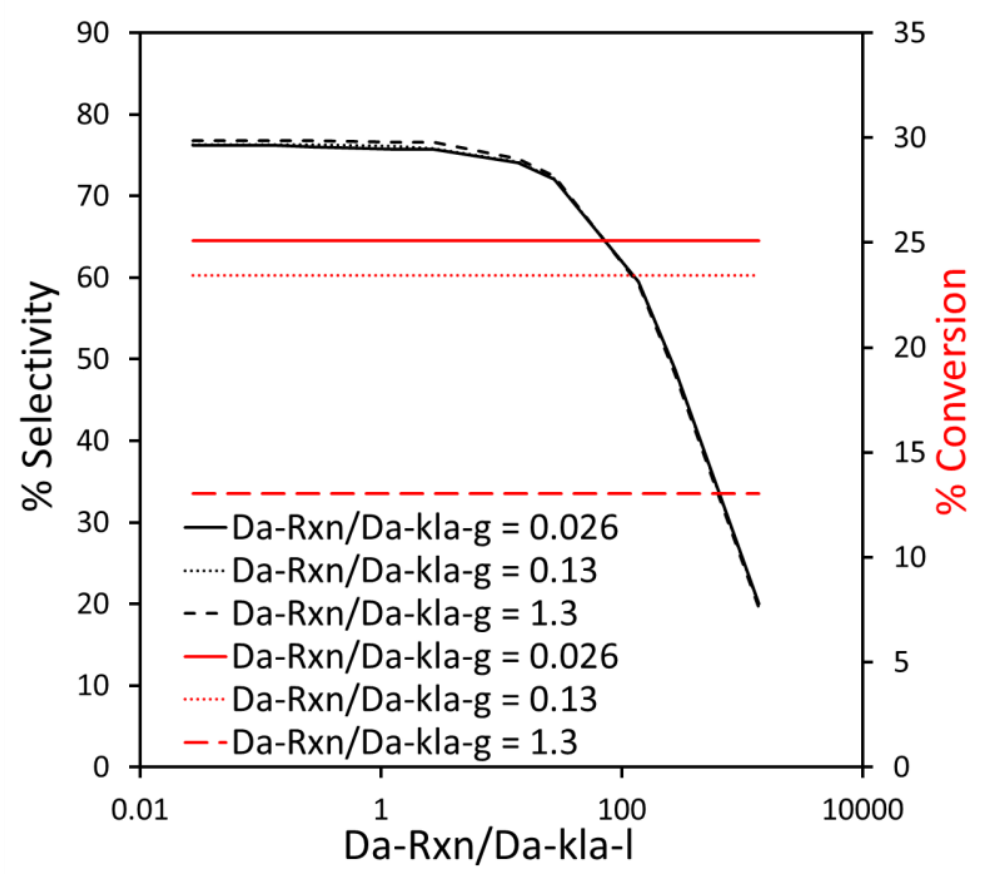

(b)

Figure 9: Effect of Gas-Liquid and Liquid-Liquid Mass transfer on Conversion of NB and Selectivity towards pAP at 70\% Reaction Phase Hold up (Continuous) (a) Focus on G-L transport, (b) Focus on LL transport 


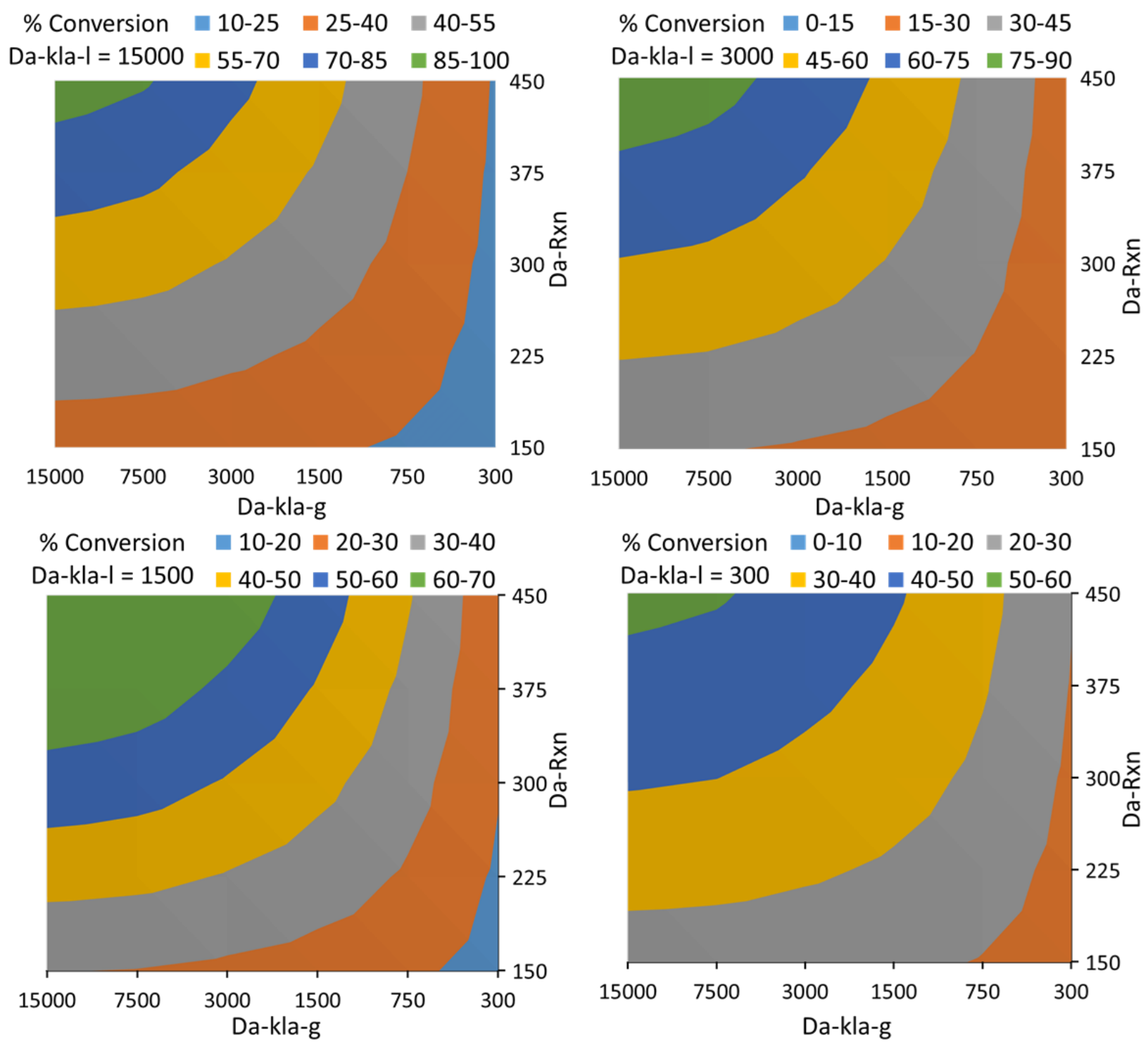

Figure 10: Effect on Conversion at different Reaction Damkholer Number (Da-Rxn), G-L and L-L Mass Transfer Damkholer Number (Da-kla-g \% Da-kla-1) for Dispersed Reaction Phase (30\% hold up) 


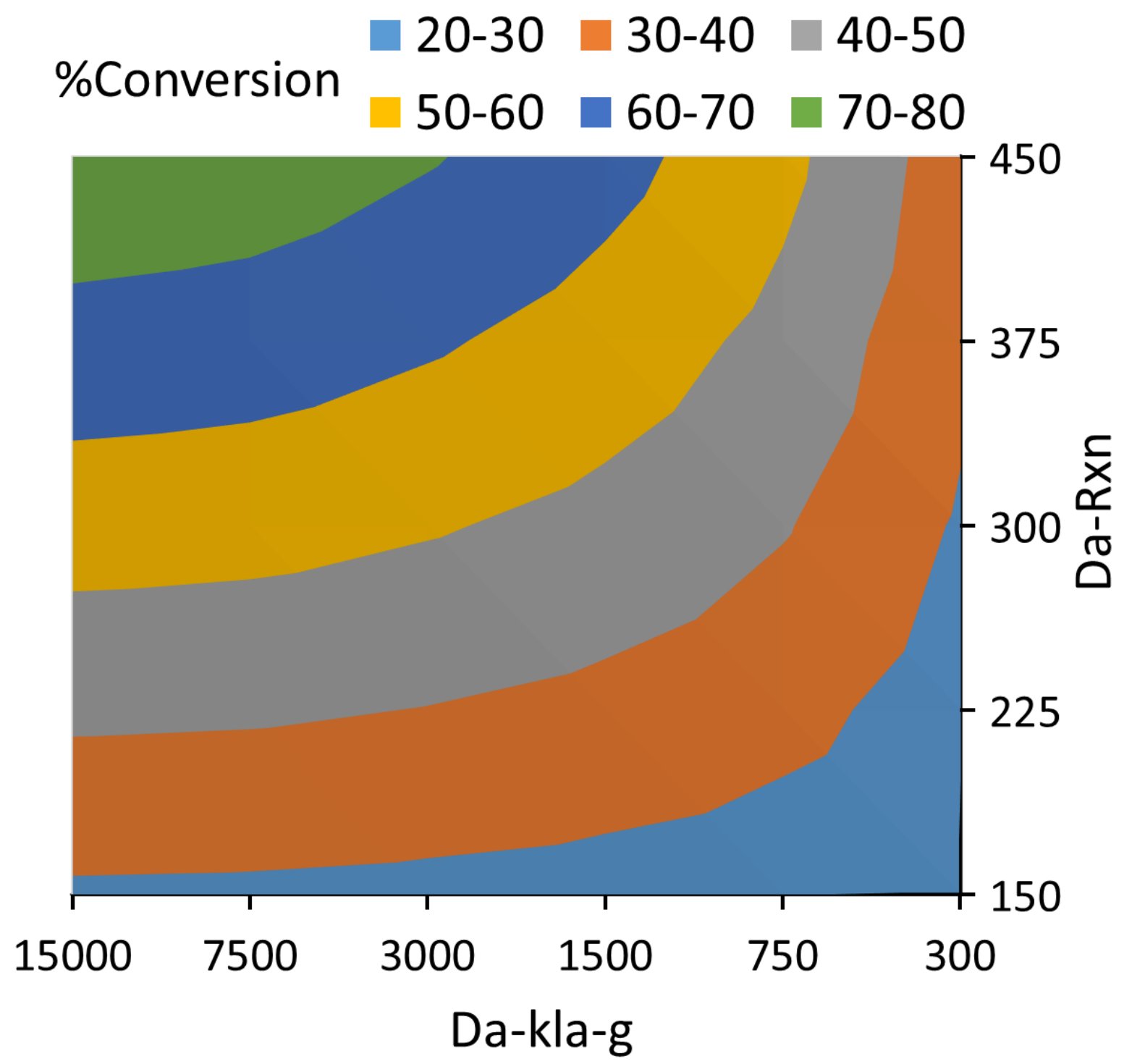

Figure 11: Effect on Conversion at different Reaction Damkholer Number (Da-Rxn), G-L Mass Transfer Damkholer Number (Da-kla-g) for Continuous Reaction Phase (70\% hold up) 


\section{\% Conversion \\ -75-90 60-75 45-60}

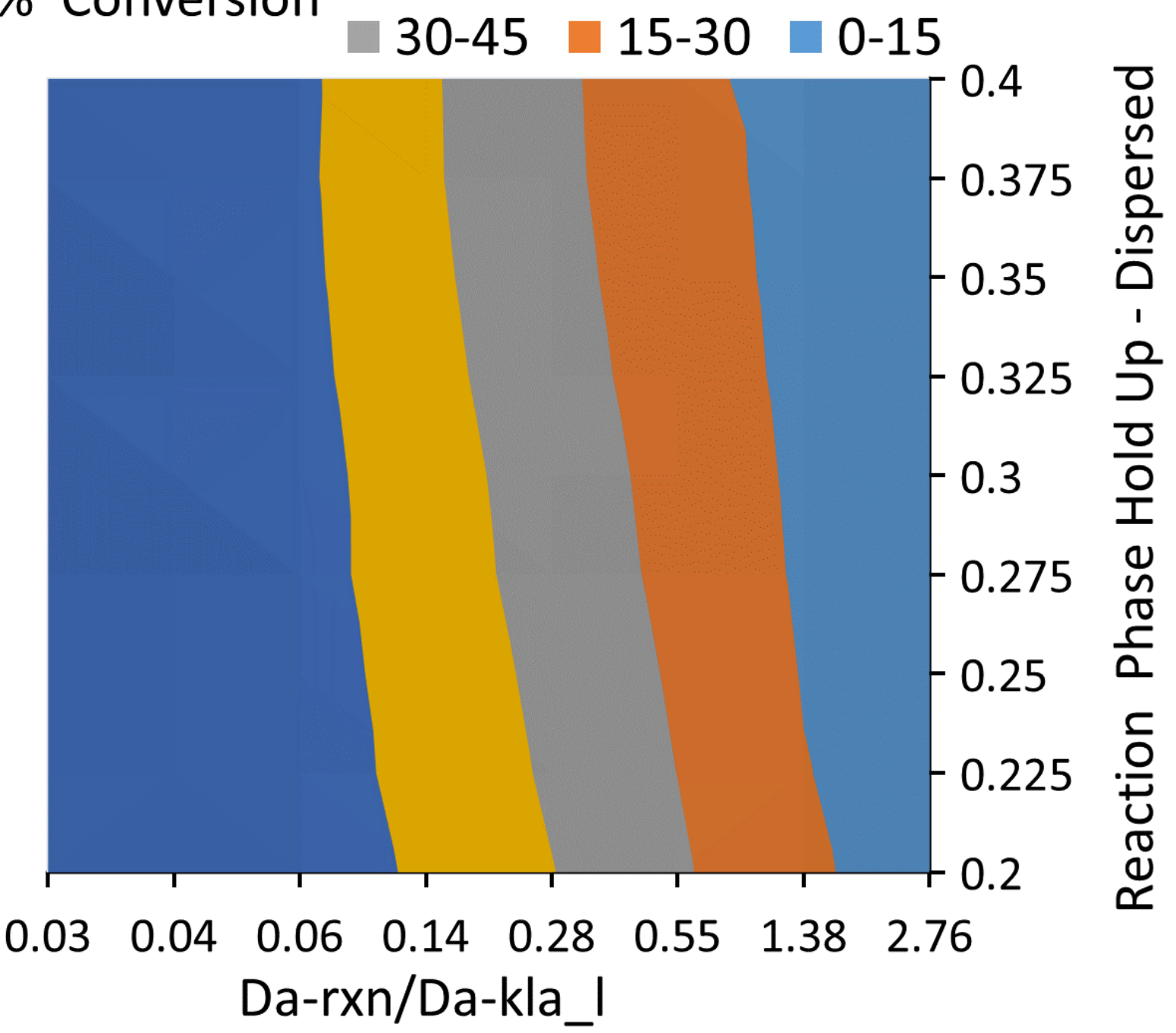

Figure 12: Effect of Dispersed Reaction Phase Holdup and Liquid-Liquid Mass transfer on Conversion of NB 


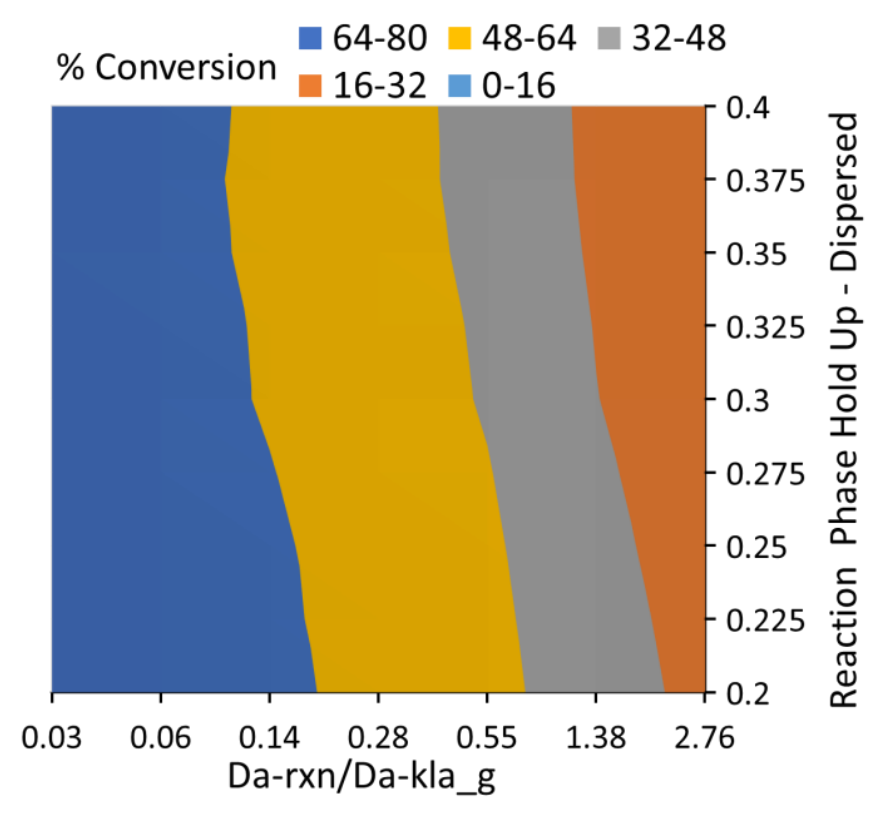

(a)

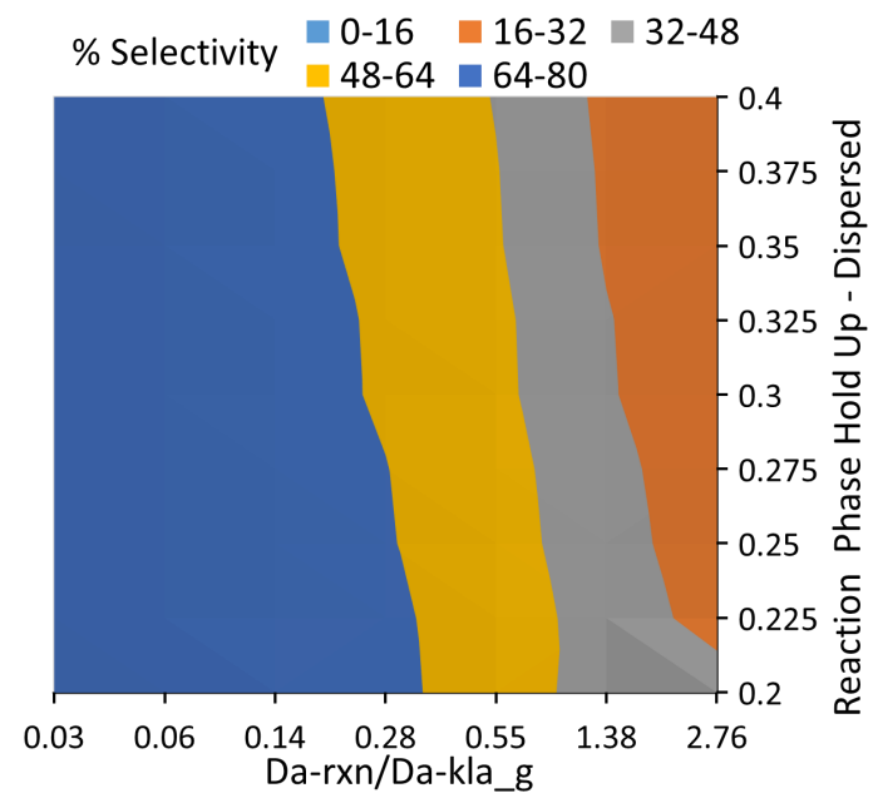

(b)

Figure 13: Effect of Dispersed Reaction Phase Holdup and Gas -Liquid Mass transfer on (a) Conversion of NB and (b) Selectivity towards pAP, Da_Rxn/Da_kla_l $=0.06$ 


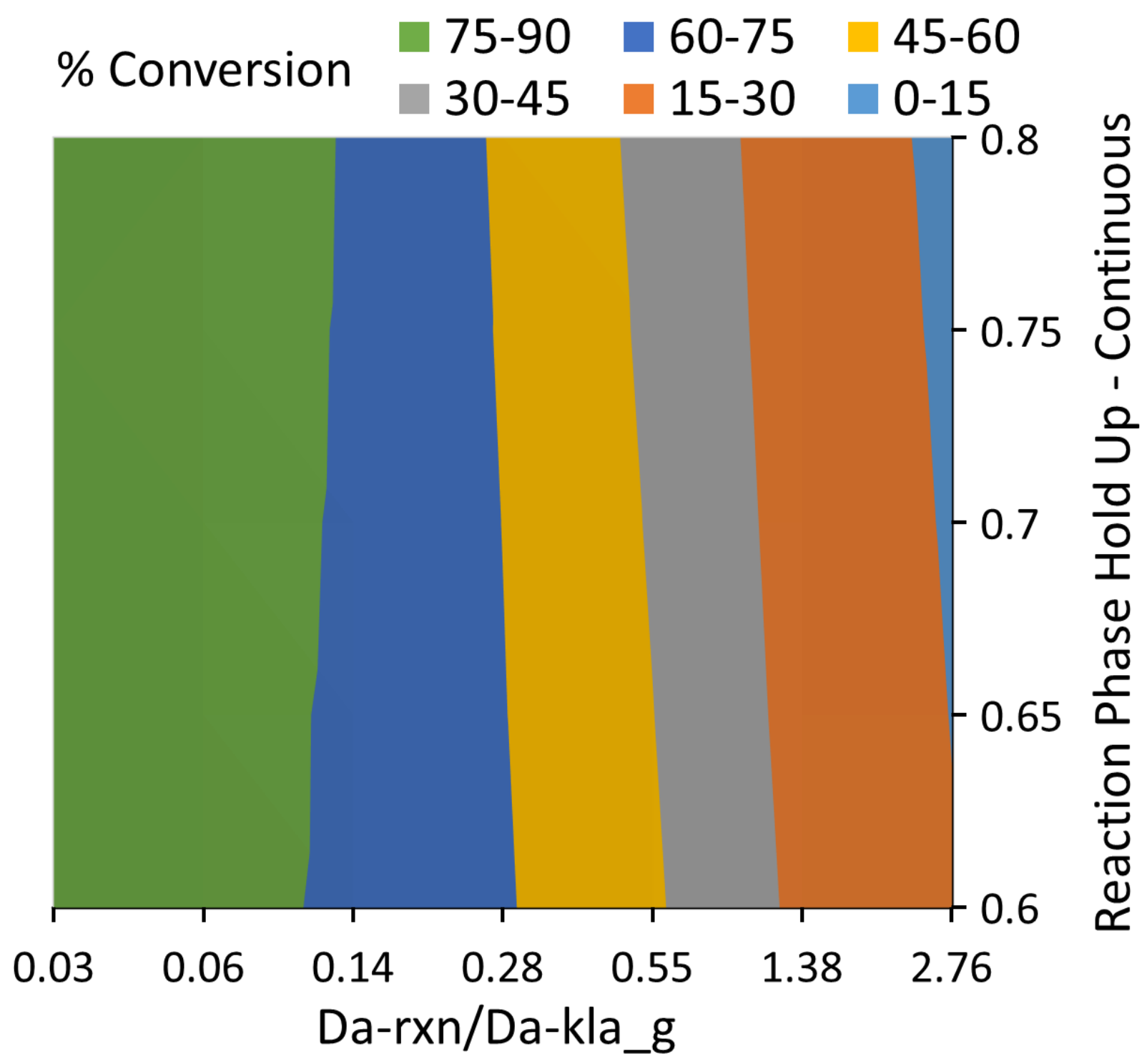

Figure 14: Effect of Continuous Reaction Phase Holdup and Liquid-Liquid Mass transfer on Conversion of NB 